\title{
Synthesis and Structure-Linear and -Nonlinear Optical Properties of Multi-Dipolar Zig-Zag Oligoaryleneethynylenes
}

Pik Kwan Lo ${ }^{a}$, King Fai Li ${ }^{b}$, Man Shing Wong ${ }^{a, *}$, and Kok Wai Cheah ${ }^{b_{, *}}$

${ }^{a}$ Department of Chemistry and Centre for Advanced Luminescence Materials, Hong Kong Baptist University, Kowloon Tong, Hong Kong SAR, China. E-mail: mswong@hkbu.edu.hk Fax: 852-3411-7348

${ }^{b}$ Department of Physics and Centre for Advanced Luminescence Materials, Hong Kong Baptist University, Kowloon Tong, Hong Kong SAR, China. E-mail:

kwcheah@hkbu.edu.hk

\section{Contents}

1. General experimental and synthetic procedures $\quad$ S2

2. ${ }^{1} \mathrm{H}$ NMR and ${ }^{13} \mathrm{C}$ NMR spectra of DA(n)s and D-Ar-A(n)s S21 


\section{General Experimental}

${ }^{1} \mathrm{H}$ NMR spectra were recorded using a $270 \mathrm{MHz}$ FT NMR spectrometer or a $400 \mathrm{MHz}$ FT NMR spectrometer and are referenced to the residual $\mathrm{CHCl}_{3} 7.24 \mathrm{ppm}$ or $\mathrm{CH}_{2} \mathrm{Cl}_{2} 5.23 \mathrm{ppm}$ or DMSO $2.50 \mathrm{ppm} .{ }^{13} \mathrm{C}$ NMR spectra were recorded using a $67.8 \mathrm{MHz}$ FT NMR spectrometer or a $100 \mathrm{MHz}$ FT NMR spectrometer and are referenced to the $\mathrm{CDCl}_{3} 77.0$ ppm. Mass spectroscopic (MS) measurements were carried using either fast atom bombardment (FAB) or matrix-assisted laser desorption ionisation-time-of-flight (MALDITOF) technique. All the physical measurements were performed in $\mathrm{CH}_{2} \mathrm{Cl}_{2}$ or DMF. All the UV-visible absorption spectra were recorded in a dual beam mode using a matched pair of $1 \times 1 \mathrm{~cm}$ quartz cells. Pure solvent was used as a reference. Values of the molar absorptivities, $\varepsilon_{\max }$, of the compounds were obtained as the average of at least three independent measurements with absorbance in the 0.5-1. Fluorescence spectra were performed with optically dilute solutions $($ Abs. $<0.20)$ in $1 \mathrm{x} 1 \mathrm{~cm}$ cells. Fluorescence quantum yields were measured by the relative method using either quinine sulfate in $1.0 \mathrm{M}$ aqueous $\mathrm{H}_{2} \mathrm{SO}_{4}\left(\phi_{334}=0.56\right)$ or 9,10 -diphenylanthrancene in cyclohexane $\left(\phi_{360}=0.90\right)$ or fluorescein in $0.1 \mathrm{M} \mathrm{NaOH}\left(\phi_{436}=0.92\right)$ as a reference. In these measurements, the slit widths were adjusted so that the spectral bandwidth of the absorption and emission instruments were identical at $1.0 \mathrm{~nm}$, and the absorbance of the sample and the reference were chosen so they were in the 0.1-0.2 range and nearly identical at the same excitation wavelength. Emission quantum yields were then calculated according to the method described by Crosby and Demas, taking into account the differences between the refractive indices of the sample and reference solutions. Thermal stabilities were determined by thermal gravimetric analyzer with heating rate of $10{ }^{\circ} \mathrm{C} / \mathrm{min}$ under $\mathrm{N}_{2}$. For the femto- 
second-pulse experiment, a self mode-locked Ti-sapphire laser (pulsed width 80-100fs, repetition rate $82 \mathrm{MHz}$ in quasi-continuous-wave) was used as the excitation source to measure the two-photon cross sections. The scanning range can be tuned from 750 to 850 $\mathrm{nm}$. The fundamental wavelength $800 \mathrm{~nm}$ was modulated by a chopper for focused on the material in a quartz cell. These respond signals are collected by PMT and transferred to Lock-in-Amplifier for recording the results by computer. In addition, regenerative amplifier can amplify the energy up to ten thousand times of peak energy $(1 \mathrm{~mJ})$ to perform further experiments. Rhodamine $6 \mathrm{G}$ in methanol $\left(\sigma_{800}=134 \mathrm{GM}\right)$ was used as the reference standard. The concentrations of the all solutions were diluted in the range $10^{-4}$ to $10^{-6} \mathrm{M}$. The experimental uncertainty of the absolute TPA cross-sections determined has been estimated to be $\pm 15 \%$.

1-[2-(2-Butoxyethoxy)ethoxy]-4-iodobenzene 1. To a stirred solution of 4-iodophenol $(9.7 \mathrm{~g}, 44.1 \mathrm{mmol})$, potassium carbonate $(6.1 \mathrm{~g}, 44.1 \mathrm{mmol})$ and potassium iodide $(7.32 \mathrm{~g}$, $44.1 \mathrm{mmol})$ in DMSO under $\mathrm{N}_{2}$ was added 1-[2-(2-chloroethoxy)-ethoxy]butane (9.65 $\mathrm{g}$, $53.0 \mathrm{mmol}$ ). The reaction mixture was heated to $120{ }^{\circ} \mathrm{C}$ overnight under $\mathrm{N}_{2}$. After cooling to room temperature, the reaction mixture was extracted with $\mathrm{CH}_{2} \mathrm{Cl}_{2}(3 \times 30 \mathrm{~mL})$. The combined organic layer was washed with water six times, dried over anhydrous $\mathrm{Na}_{2} \mathrm{SO}_{4}$ and evaporated to dryness. The crude product was filtered through short silica-gel column chromatography using $\mathrm{CH}_{2} \mathrm{Cl}_{2}$ as eluent affording a yellow viscous liquid of $10.4 \mathrm{~g}(65 \%$ yield). ${ }^{1} \mathrm{H}$ NMR $\left(270 \mathrm{MHz}, \mathrm{CDCl}_{3}, \delta\right) 7.50(\mathrm{~d}, J=8.91 \mathrm{~Hz}, 2 \mathrm{H}), 6.66(\mathrm{~d}, J=8.91 \mathrm{~Hz}, 2 \mathrm{H})$, $4.04(\mathrm{t}, J=2.70 \mathrm{~Hz}, 2 \mathrm{H}), 3.82(\mathrm{t}, J=4.05 \mathrm{~Hz}, 2 \mathrm{H}), 3.66(\mathrm{t}, J=2.70 \mathrm{~Hz}, 2 \mathrm{H}), 3.58(\mathrm{t}, J=$ $2.70 \mathrm{~Hz}, 2 \mathrm{H}), 3.44(\mathrm{t}, J=6.75 \mathrm{~Hz}, 2 \mathrm{H}), 1.51-1.56(\mathrm{~m}, 2 \mathrm{H}), 1.31-1.34(\mathrm{~m}, 2 \mathrm{H}), 0.88(\mathrm{t}, J=$ 
$7.29 \mathrm{~Hz}, 3 \mathrm{H}) .{ }^{13} \mathrm{C} \mathrm{NMR}\left(67.8 \mathrm{MHz}, \mathrm{CDCl}_{3}, \delta\right) 157.9,137.3,116.3,82.3,70.4,70.2,69.5$, 68.9, 66.9, 31.2, 18.8, 13.5. MS (FAB) $\mathrm{m} / \mathrm{z} 363.9\left(\mathrm{M}^{+}\right)$.

1-[2-(2-Butoxyethoxy)ethoxy]-4-ethynylbenzene 2. To a stirred solution of 1 (10.3 g, $28.3 \mathrm{mmol}), \mathrm{PdCl}_{2}(0.2 \mathrm{~g}, 1.13 \mathrm{mmol}), \mathrm{PPh}_{3}(0.3 \mathrm{~g}, 1.15 \mathrm{mmol})$, and $\mathrm{CuI}(0.1 \mathrm{~g}, 0.56 \mathrm{mmol})$ in triethylamine $(100 \mathrm{~mL})$ under $\mathrm{N}_{2}$ was added (trimethylsilyl)acetylene (5.6 g, $\left.57.0 \mathrm{mmol}\right)$. After stirring at room temperature for $6 \mathrm{~h}$, the reaction mixture was extracted with $\mathrm{CH}_{2} \mathrm{Cl}_{2}$ $(3 \times 30 \mathrm{~mL})$. The combined organic layer was washed with water three times, dried over anhydrous $\mathrm{Na}_{2} \mathrm{SO}_{4}$ and evaporated to dryness. The crude product was purified by silica-gel column chromatography using $\mathrm{CH}_{2} \mathrm{Cl}_{2}$ as eluent to afford a yellow viscous liquid 1-[2-(2butyoxyethoxy)ethoxy]-4-trimethylsilylethynylbenzene of $9.5 \mathrm{~g}$ (100\% yield). ${ }^{1} \mathrm{H}$ NMR $\left(270 \mathrm{MHz}, \mathrm{CDCl}_{3}, \delta\right) 7.35(\mathrm{~d}, J=8.91 \mathrm{~Hz}, 2 \mathrm{H}), 6.79(\mathrm{~d}, J=8.64 \mathrm{~Hz}, 2 \mathrm{H}), 4.08(\mathrm{t}, 2 \mathrm{H})$, $3.82(\mathrm{t}, J=2.70 \mathrm{~Hz}, 2 \mathrm{H}), 3.66(\mathrm{t}, J=2.70 \mathrm{~Hz}, 2 \mathrm{H}), 3.57(\mathrm{t}, J=2.70 \mathrm{~Hz}, 2 \mathrm{H}), 3.43(\mathrm{t}, J=$ $6.75 \mathrm{~Hz}, 2 \mathrm{H}), 1.50-1.54(\mathrm{~m}, 2 \mathrm{H}), 1.28-1.34(\mathrm{~m}, 2 \mathrm{H}), 0.88(\mathrm{t}, J=7.29 \mathrm{~Hz}, 3 \mathrm{H}), 0.21(\mathrm{~s}, 9 \mathrm{H})$. ${ }^{13} \mathrm{C}$ NMR $\left(67.8 \mathrm{MHz}, \mathrm{CDCl}_{3}, \delta\right)$ 158.7, 133.2, 115.2, 114.3, 105.0, 92.3, 71.1, 70.8, 70.0, 69.5, 67.3, 31.7, 19.3, 14.0, 0.10. MS (FAB) $\mathrm{m} / \mathrm{z} 334.3\left(\mathrm{M}^{+}\right)$.

To a stirred solution of 1-[2-(2-butyoxyethoxy)ethoxy]-4-trimethylsilylethynylbenzene (9.5 g, $28.4 \mathrm{mmol})$ in $\mathrm{CH}_{2} \mathrm{Cl}_{2}(30 \mathrm{~mL})$ and methanol $(30 \mathrm{~mL})$ was added potassium carbonate (4.7 g, $34.0 \mathrm{mmol}$ ). After stirring at room temperature for $6 \mathrm{~h}$, the reaction mixture was extracted with $\mathrm{CH}_{2} \mathrm{Cl}_{2}(3 \times 30 \mathrm{~mL})$. The combined organic layer was washed with water three times, dried over anhydrous $\mathrm{Na}_{2} \mathrm{SO}_{4}$ and evaporated to dryness. The crude product was purified by silica-gel column chromatography using $\mathrm{CH}_{2} \mathrm{Cl}_{2}$ as eluent to afford a yellowish-brown viscous liquid of $7.3 \mathrm{~g}$ (98 \% yield). ${ }^{1} \mathrm{H} \mathrm{NMR}\left(270 \mathrm{MHz}, \mathrm{CDCl}_{3}, \delta\right) 7.37$ $(\mathrm{d}, J=8.91 \mathrm{~Hz}, 2 \mathrm{H}), 6.81(\mathrm{~d}, J=8.64 \mathrm{~Hz}, 2 \mathrm{H}), 4.07(\mathrm{t}, J=2.70 \mathrm{~Hz}, 2 \mathrm{H}), 3.82(\mathrm{t}, J=4.05$ 
$\mathrm{Hz}, 2 \mathrm{H}), 3.66(\mathrm{t}, J=2.70 \mathrm{~Hz}, 2 \mathrm{H}), 3.57(\mathrm{t}, J=2.70 \mathrm{~Hz}, 2 \mathrm{H}), 3.42(\mathrm{t}, J=5.40 \mathrm{~Hz}, 2 \mathrm{H}), 2.97$

$(\mathrm{s}, 1 \mathrm{H}), 1.50-1.56(\mathrm{~m}, 2 \mathrm{H}), 1.28-1.36(\mathrm{~m}, 2 \mathrm{H}), 0.87(\mathrm{t}, J=6.48 \mathrm{~Hz}, 3 \mathrm{H}) .{ }^{13} \mathrm{C} \mathrm{NMR}(100$ $\left.\mathrm{MHz}, \mathrm{CDCl}_{3}, \delta\right) 158.8,133.2,114.2,114.0,83.3,75.8,70.9,70.5,69.8,69.2,67.1,31.4$, 19.0, 13.7. MS (FAB) $\mathrm{m} / \mathrm{z} 262.2\left(\mathrm{M}^{+}\right)$.

3,6-Bis(ethynyl)dibenzothiophene 6 . To a stirred solution of 3,6-bis(trimethylsilylethynyl)dibenzothiophene $(41.4 \mathrm{mg}, 0.10 \mathrm{mmol})$ in $\mathrm{CH}_{2} \mathrm{Cl}_{2}(5 \mathrm{~mL})$ and methanol (5 $\mathrm{mL})$ was added potassium carbonate $(16.8 \mathrm{mg}, 0.12 \mathrm{mmol})$. The reaction mixture was stirred at room temperature for $1 \mathrm{~h}$. The reaction mixture was extracted with $\mathrm{CH}_{2} \mathrm{Cl}_{2}(3 \times$ $30 \mathrm{~mL}$ ). The combined organic layer was washed with water three times, dried over anhydrous $\mathrm{Na}_{2} \mathrm{SO}_{4}$ and evaporated to dryness. The crude product was purified by precipitation using $\mathrm{CH}_{2} \mathrm{Cl}_{2} /$ methanol to afford a brown solid of $26.8 \mathrm{mg}\left(100 \%\right.$ yield). ${ }^{1} \mathrm{H}$ $\operatorname{NMR}\left(270 \mathrm{MHz}, \mathrm{CDCl}_{3}, \delta\right) 8.26(\mathrm{~d}, J=1.35 \mathrm{~Hz}, 2 \mathrm{H}), 7.78(\mathrm{~d}, J=8.37 \mathrm{~Hz}, 2 \mathrm{H}), 8.57(\mathrm{~d}, J$ $=8.10 \mathrm{~Hz}, 2 \mathrm{H}), 3.14(\mathrm{~s}, 2 \mathrm{H}) .{ }^{13} \mathrm{C} \mathrm{NMR}\left(100 \mathrm{MHz}, \mathrm{CDCl}_{3}, \delta\right) 140.2,134.9,130.6,125.5$, 122.8, 118.6, 83.5. MS (FAB) $\mathrm{m} / \mathrm{z} 232.2\left(\mathrm{M}^{+}\right)$.

3-Iodo-6-(trimethylsilylethynyl)dibenzothiophene 7. To a stirred solution of $4(0.73 \mathrm{~g}$, $1.67 \mathrm{mmol}), \mathrm{PdCl}_{2}(16.5 \mathrm{mg}, 0.09 \mathrm{mmol}), \mathrm{PPh}_{3}(24.4 \mathrm{mg}, 0.09 \mathrm{mmol})$, and $\mathrm{CuI}(8.86 \mathrm{mg}$, $0.05 \mathrm{mmol})$ in triethylamine $(15 \mathrm{~mL})$ under $\mathrm{N}_{2}$ was added (trimethylsilyl)acetylene $(0.27 \mathrm{~g}$, $2.75 \mathrm{mmol})$. The reaction mixture was stirred at room temperature for $6 \mathrm{~h}$. The reaction mixture was extracted with $\mathrm{CH}_{2} \mathrm{Cl}_{2}(3 \times 30 \mathrm{~mL})$. The combined organic layer was washed with water three times, dried over anhydrous $\mathrm{Na}_{2} \mathrm{SO}_{4}$ and evaporated to dryness. The crude product was purified by silica-gel column chromatography using petroleum ether as eluent to afford 3,6-bis(trimethylsilylethynyl)dibenzothiophene as a yellow viscous liquid of 0.40 $\mathrm{g}\left(30 \%\right.$ yield) and using petroleum ether/ $\mathrm{CH}_{2} \mathrm{Cl}_{2}(\mathrm{v} / \mathrm{v} 4: 1)$ as eluent to afford 7 as a yellow 
viscous liquid of $0.20 \mathrm{~g}(60 \%$ yield $) .{ }^{1} \mathrm{H} \mathrm{NMR}\left(270 \mathrm{MHz}, \mathrm{CDCl}_{3}, \delta\right) 8.29(\mathrm{~s}, 1 \mathrm{H}), 8.06(\mathrm{~s}$,

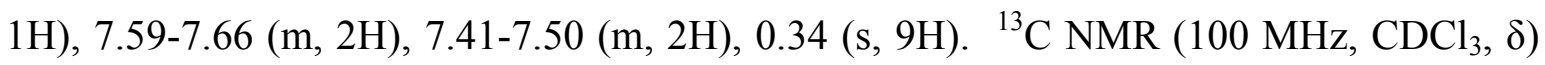
$139.7,139.1,137.0,135.5,134.1,130.7,130.5,125.3,124.4,122.6,119.6,104.8,94.5$, 89.1, 0.00. MS (FAB) $m / z$ 406.1 $\left(\mathrm{M}^{+}\right)$.

3,6-Bis(ethynyl)dibenzothiophene sulfone 8. The oxidation procedure for 5 was followed using 3,6-bis(trimethylsilylethynyl)dibenzothiophene (1.2 g, $3.19 \mathrm{mmol})$ in $\mathrm{CH}_{2} \mathrm{Cl}_{2}$ was added $\mathrm{mCPBA}(1.8 \mathrm{~g}, 10.0 \mathrm{mmol})$ at $0{ }^{\circ} \mathrm{C}$. The crude product was purified by silica-gel column chromatography using $\mathrm{CH}_{2} \mathrm{Cl}_{2}$ as eluent to afford 3,6-bis(trimethylsilylethynyl)dibenzothiophene sulfone as a yellow viscous liquid of $1.29 \mathrm{~g}$ (99\% yield). ). ${ }^{1} \mathrm{H}$ NMR $\left(270 \mathrm{MHz}, \mathrm{CDCl}_{3}, \delta\right) 7.84(\mathrm{~s}, 2 \mathrm{H}), 7.73(\mathrm{t}, J=7.83 \mathrm{~Hz}), 7.58(\mathrm{~d}, J=8.10 \mathrm{~Hz}), 0.27(\mathrm{~s}$, 18H). ${ }^{13} \mathrm{C} \mathrm{NMR}\left(67.8 \mathrm{MHz}, \mathrm{CDCl}_{3}, \delta\right) 136.8,133.7,130.9,129.1,124.8,122.0,102.6$, 88.3, 0.16. MS (FAB) $\mathrm{m} / \mathrm{z} 409.2\left(\mathrm{M}^{+}\right)$. The deprotection procedure for 6 was followed using 3,6-bis(trimethylsilylethynyl)-dibenzothiophene sulfone $(0.10 \mathrm{~g}, 0.28 \mathrm{mmol})$ and potassium carbonate $(46.1 \mathrm{mg}, 1.21 \mathrm{mmol})$ in $\mathrm{CH}_{2} \mathrm{Cl}_{2}(8 \mathrm{~mL})$ and methanol $(8 \mathrm{~mL})$. The reaction mixture was stirred at room temperature for $2 \mathrm{~h}$. The crude product was purified by precipitation using $\mathrm{CH}_{2} \mathrm{Cl}_{2}$-methanol to afford a light yellow solid of $76.6 \mathrm{mg}$ (99\% yield). ${ }^{1} \mathrm{H}$ NMR $\left(270 \mathrm{MHz}, \mathrm{CDCl}_{3}, \delta\right) 7.86(\mathrm{~s}, 2 \mathrm{H}), 7.76(\mathrm{~d}, J=8.10 \mathrm{~Hz}, 2 \mathrm{H}), 7.62$ (d, $J=$ $6.75 \mathrm{~Hz}, 2 \mathrm{H}), 3.30(\mathrm{~s}, 2 \mathrm{H}) .{ }^{13} \mathrm{C} \mathrm{NMR}\left(67.8 \mathrm{MHz}, \mathrm{CDCl}_{3}, \delta\right)$ 137.4, 134.2, 131.0, 128.2, 125.1, 122.2, 81.6, 81.4. MS (FAB) $m / z 265.2\left(\mathrm{M}^{+}\right)$.

\section{3-(4-\{1-[2-(2-butoxyethoxy)ethoxy]\}phenylethynyl)-6-iododibenzothiophene sulfone 9.}

To a stirred solution of $5(0.9 \mathrm{mg}, 1.92 \mathrm{mmol}), \mathrm{Pd}\left(\mathrm{PPh}_{3}\right)_{2} \mathrm{Cl}_{2}(26.0 \mathrm{mg}, 0.04 \mathrm{mmol})$ and $\mathrm{CuI}$ (3.6 $\mathrm{mg}, 0.02 \mathrm{mmol})$ in triethylamine $(5 \mathrm{~mL})$ under $\mathrm{N}_{2}$ was added $2(0.25 \mathrm{~g}, 0.95 \mathrm{mmol})$ in dry THF. The reaction mixture was stirred overnight at room temperature under $\mathrm{N}_{2}$. The 
reaction mixture was extracted with $\mathrm{CH}_{2} \mathrm{Cl}_{2}(3 \times 30 \mathrm{~mL})$. The combined organic layer was washed with water three times, dried over anhydrous $\mathrm{Na}_{2} \mathrm{SO}_{4}$ and evaporated to dryness. The crude product was purified by silica-gel column chromatography using $\mathrm{CH}_{2} \mathrm{Cl}_{2} / \mathrm{EtOAc}$ (v/v 100:1) as eluent. The pure product was obtained by precipitation from $\mathrm{CH}_{2} \mathrm{Cl}_{2} /$ methanol to afford DA-(2) as a brownish-orange solid of $1.0 \mathrm{~g}$ (23\% yield) and 9 as a yellow solid of $0.5 \mathrm{~g}(47 \%$ yield $) .{ }^{1} \mathrm{H} \mathrm{NMR}\left(270 \mathrm{MHz}, \mathrm{CDCl}_{3}, \delta\right) 8.15(\mathrm{~s}, 1 \mathrm{H}), 7.84-$ $7.88(\mathrm{~m}, 2 \mathrm{H}), 7.60-7.78(\mathrm{~m}, 2 \mathrm{H}), 7.45-7.54(\mathrm{~m}, 3 \mathrm{H}, \mathrm{ArH}), 6.91(\mathrm{~d}, J=8.64 \mathrm{~Hz}, 2 \mathrm{H}, \mathrm{ArH})$ $4.15(\mathrm{t}, J=5.40 \mathrm{~Hz}, 2 \mathrm{H}), 3.87(\mathrm{t}, 2 \mathrm{H}), 3.70(\mathrm{t}, J=5.40 \mathrm{~Hz}, 2 \mathrm{H}), 3.60(\mathrm{t}, J=5.40 \mathrm{~Hz}, 2 \mathrm{H})$, $3.46(\mathrm{t}, J=6.75 \mathrm{~Hz}, 2 \mathrm{H}), 1.53-1.59(\mathrm{~m}, 2 \mathrm{H}), 1.33-1.36(\mathrm{~m}, 2 \mathrm{H}), 0.90(\mathrm{t}, J=7.56 \mathrm{~Hz}, 3 \mathrm{H})$. ${ }^{13} \mathrm{C}$ NMR $\left(100 \mathrm{MHz}, \mathrm{CDCl}_{3}, \delta\right) 159.5,139.2,137.0,135.8,133.3,133.2,130.7,130.2$, $129.7,124.1,123.0,121.9,114.7,113.9,100.7,94.0,86.4,71.1,70.8,69.9,69.4,67.4,31.5$, 19.1, 13.8. MS (FAB) $\mathrm{m} / \mathrm{z} 602.2\left(\mathrm{M}^{+}\right)$.

3,6-Bis-6\{3-ethynyldibenzothienyl\}ethynyldibenzothiophene sulfone 10 . The coupling procedure for DA(2) was followed using 7 (0.6 g, $1.48 \mathrm{mmol}), 8(0.19 \mathrm{~g}, 0.72 \mathrm{mmol})$, $\mathrm{PdCl}_{2}(5.0 \mathrm{mg}, 0.03 \mathrm{mmol}), \mathrm{PPh}_{3}(7.4 \mathrm{mg}, 0.03 \mathrm{mmol}), \mathrm{CuI}(2.7 \mathrm{mg}, 0.01 \mathrm{mmol})$ and triethylamine $(10 \mathrm{~mL})$ in dry THF. The crude product was purified by silica-gel column chromatography using petroleum ether $/ \mathrm{CH}_{2} \mathrm{Cl}_{2}(\mathrm{v} / \mathrm{v} 1: 2)$ as eluent to afford 3,6-Bis-6\{3trimethylethynyldibenzothienyl ethynyldibenzothiophene sulfone as a yellow solid of 0.51 g (87\% yield). ${ }^{1} \mathrm{H}$ NMR (270 MHz, $\left.\mathrm{CDCl}_{3}, \delta\right) 8.35$ (s, 2H), 8.29 (s, 2H), 8.00 (s, 2H), 7.55-7.87 (m, 12H), 0.27 (s, 18H). ${ }^{13} \mathrm{C} \mathrm{NMR}\left(100 \mathrm{MHz}, \mathrm{CDCl}_{3}, \delta\right)$ 140.7, 139.9, 136.8, $135.1,134.7,133.5,131.3,130.6,130.0,129.4,125.4,125.2,124.4,123.0,122.7,122.3$, 119.7, 118.4, 104.8, 94.6, 93.6, 87.8. 0.02. MS (FAB) $m / z 821.3\left(\mathrm{M}^{+}\right)$. The deprotection procedure for 6 was followed using 3,6-bis-6\{3-trimethyl- 
ethynyldibenzothienyl\} ethynyldibenzothiophene sulfone $(27.1 \mathrm{mg}, 0.03 \mathrm{mmol})$ and potassium carbonate $(5.12 \mathrm{mg}, 0.04 \mathrm{mmol})$ in $\mathrm{CHCl}_{3}(8 \mathrm{~mL})$ and methanol $(8 \mathrm{~mL})$. The reaction mixture was stirred overnight at room temperature. The crude product was purified by precipitation using $\mathrm{CH}_{2} \mathrm{Cl}_{2} /$ methanol to afford a light yellow solid of $22.7 \mathrm{mg}$

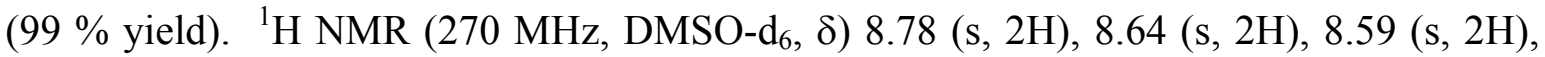
8.03-8.19 (m, 6H), $7.87(\mathrm{~d}, J=8.10 \mathrm{~Hz}, 2 \mathrm{H}), 7.76(\mathrm{~d}, J=8.10 \mathrm{~Hz}, 2 \mathrm{H}), 7.63(\mathrm{~d}, J=8.37$ $\mathrm{Hz}, 2 \mathrm{H}), 4.30$ (s, 2H). ${ }^{13} \mathrm{C} \mathrm{NMR}\left(100 \mathrm{MHz}, \mathrm{CDCl}_{3}, \delta\right) 140.3,139.6,136.5,134.7,134.5$, $130.9,130.5,130.2,128.6,125.8,125.2,123.8,123.6,118.5,118.0,93.3,88.1,83.5,81.0$. MS (FAB) $m / z 677.0\left(\mathrm{M}^{+}\right)$.

1-[2-(2-Butoxyethoxy)ethoxy]-4-(4-iodophenylethynyl)benzene 11a. The coupling procedure for DA-(2) was followed using 2 (0.82 g, $3.31 \mathrm{mmol})$, 1,4-diiodobenzene (4.17 g, $12.6 \mathrm{mmol}), \mathrm{Pd}\left(\mathrm{PPh}_{3}\right)_{2} \mathrm{Cl}_{2}(0.09 \mathrm{~g}, 0.13 \mathrm{mmol}), \mathrm{CuI}(12 \mathrm{mg}, 0.06 \mathrm{mmol})$ and triethylamine $(10 \mathrm{~mL})$ under $\mathrm{N}_{2}$ in dry THF. The crude product was purified by silica-gel column chromatography using $\mathrm{CH}_{2} \mathrm{Cl}_{2}$ as eluent to afford 11a as a yellow viscous liquid of $0.9 \mathrm{~g}$ (64\% yield). ${ }^{1} \mathrm{H}$ NMR (270 MHz, $\left.\mathrm{CHCl}_{3}, \delta\right) 7.64(\mathrm{~d}, J=8.37 \mathrm{~Hz}, 2 \mathrm{H}), 7.42$ (d, $J=8.64$ $\mathrm{Hz}, 2 \mathrm{H}), 7.20(\mathrm{~d}, J=8.64 \mathrm{~Hz}, 2 \mathrm{H}), 6.87(\mathrm{~d}, J=8.91 \mathrm{~Hz}, 2 \mathrm{H}), 4.13(\mathrm{t}, J=5.40 \mathrm{~Hz}, 2 \mathrm{H})$, $3.85(\mathrm{t}, J=5.40 \mathrm{~Hz}, 2 \mathrm{H}), 3.68(\mathrm{t}, J=5.40 \mathrm{~Hz}, 2 \mathrm{H}), 3.59(\mathrm{t}, J=5.40 \mathrm{~Hz}, 2 \mathrm{H}), 3.46(\mathrm{t}, J=$ $6.75 \mathrm{~Hz}, 2 \mathrm{H}), 1.53-1.58(\mathrm{~m}, 2 \mathrm{H}), 1.33-1.35(\mathrm{~m}, 2 \mathrm{H}), 0.90(\mathrm{t}, J=7.02 \mathrm{~Hz}, 3 \mathrm{H}) .{ }^{13} \mathrm{C} \mathrm{NMR}$ (67.8 $\left.\mathrm{MHz}, \mathrm{CDCl}_{3}, \delta\right)$ 158.8, 137.2, 132.8, 132.7, 122.9, 114.9, 114.5, 93.5, 90.8, 87.1, 71.2, 70.8, 70.0, 69.5, 67.4, 31.7, 19.3, 14.0. $\mathrm{MS}(\mathrm{FAB}) \mathrm{m} / \mathrm{z} 464.2\left(\mathrm{M}^{+}\right)$.

1-[2-(2-Butoxyethoxy)ethoxy]-4-(7-iodo-2-fluorenylethynyl)benzene 11b The coupling procedure for DA-(2) was followed using 2 (0.65 g, $2.48 \mathrm{mmol})$, 9,9-bis(n-butyl)-2,7diiodofluorene (2.63 g, $4.94 \mathrm{mmol}), \mathrm{PdCl}_{2}$ (17 mg, $\left.0.01 \mathrm{mmol}\right), \mathrm{CuI}(9.4 \mathrm{mg}, 0.05 \mathrm{mmol})$, 
$\mathrm{P}\left(\mathrm{PPh}_{3}\right)_{3}(25.9 \mathrm{mg}, 0.01)$ and triethylamine $(10 \mathrm{~mL})$ under $\mathrm{N}_{2}$ in dry THF. The crude product was purified by silica-gel column chromatography using $\mathrm{CH}_{2} \mathrm{Cl}_{2}$ as eluent to afford 11b as a yellow viscous liquid of $1.11 \mathrm{~g}(67 \%$ yield $) .{ }^{1} \mathrm{H} \mathrm{NMR}\left(270 \mathrm{MHz}, \mathrm{CHCl}_{3}, \delta\right) 7.60$ $7.66(\mathrm{~m}, 3 \mathrm{H}), 7.39-7.49(\mathrm{~m}, 5 \mathrm{H}), 6.89(\mathrm{~d}, J=8.91 \mathrm{~Hz}, 2 \mathrm{H}), 4.15(\mathrm{t}, J=4.05 \mathrm{~Hz}, 4 \mathrm{H}), 3.87$ $(\mathrm{t}, J=4.05 \mathrm{~Hz}, 4 \mathrm{H}), 3.71(\mathrm{t}, J=5.40 \mathrm{~Hz}, 4 \mathrm{H}), 3.60(\mathrm{t}, J=5.40 \mathrm{~Hz}, 4 \mathrm{H}), 3.46(\mathrm{t}, J=6.75 \mathrm{~Hz}$, 4H), 1.91-2.09 (m, 4H), 1.51-1.60 (m, 2H), 1.28-1.42 (m, 2H), 1.03-1.12 (m, 4H), 0.88-

$0.93(\mathrm{~m}, 3 \mathrm{H}), 0.6-0.69(\mathrm{~m}, 9 \mathrm{H}) .{ }^{13} \mathrm{C} \mathrm{NMR}\left(67.8 \mathrm{MHz}, \mathrm{CDCl}_{3}, \delta\right)$ 158.6, 153.1, 149.9, $139.9,139.8,135.7,132.8,131.8,130.4,125.5,122.3,121.4,119.6,115.3,114.5,92.9$, $89.7,88.9,71.2,70.8,70.0,69.5,67.4,55.2,40.1,31.7,25.8,23.0,19.3,14.0,13.8$. MS (FAB) $m / z 664.3\left(\mathrm{M}^{+}\right)$.

1-[2-(2-Butoxyethoxy)ethoxy]-4-(2'-iodo-2-bifluorenylethynyl)benzene 11c The coupling procedure for DA-(2) was followed using 2 (0.84 g, $3.59 \mathrm{mmol})$, 2,2'-diiodobis[9,9-di(n-butyl)fluorene] (3.86 g, $4.79 \mathrm{mmol}), \mathrm{Pd}\left(\mathrm{PPh}_{3}\right)_{2} \mathrm{Cl}_{2}(0.09 \mathrm{~g}, 0.13 \mathrm{mmol}), \mathrm{CuI}$ $(12 \mathrm{mg}, 0.06 \mathrm{mmol})$ and triethylamine $(10 \mathrm{~mL})$ under $\mathrm{N}_{2}$ in dry THF. The crude product was purified by silica-gel column chromatography using $\mathrm{CH}_{2} \mathrm{Cl}_{2}$ as eluent to afford $11 \mathrm{c}$ as a yellow viscous liquid of $1.42 \mathrm{~g}$ (47\% yield). ${ }^{1} \mathrm{H} \mathrm{NMR}\left(400 \mathrm{MHz}, \mathrm{CHCl}_{3}, \delta\right)$ 7.69-7.77 $(\mathrm{m}, 2 \mathrm{H}), 7.62-7.86(\mathrm{~m}, 5 \mathrm{H}), 7.58-7.59(\mathrm{~m}, 2 \mathrm{H}), 7.46-7.52(\mathrm{~m}, 5 \mathrm{H}), 6.89(\mathrm{~d}, J=8.10 \mathrm{~Hz}$ 2H), $4.14(\mathrm{t}, J=4.0 \mathrm{~Hz}, 2 \mathrm{H}), 3.87(\mathrm{t}, J=6.0 \mathrm{~Hz}, 2 \mathrm{H}), 3.72(\mathrm{t}, J=4.0 \mathrm{~Hz}, 2 \mathrm{H}), 3.61(\mathrm{t}, J=$ $6.0 \mathrm{~Hz}, 2 \mathrm{H}), 3.46(\mathrm{t}, J=8.0 \mathrm{~Hz}, 2 \mathrm{H}), 1.93-2.04(\mathrm{~m}, 8 \mathrm{H}), 1.54-1.58(\mathrm{~m}, 2 \mathrm{H}), 1.32-1.38(\mathrm{~m}$, 2H), 1.06-1.13 (m, 8H), $0.90(\mathrm{t}, J=7.29 \mathrm{~Hz}, 3 \mathrm{H}), 0.65-0.71(\mathrm{~m}, 20 \mathrm{H}) .{ }^{13} \mathrm{C}$ NMR (100 $\left.\mathrm{MHz}, \mathrm{CDCl}_{3}, \delta\right) 158.8,153.4,151.8,151.0,150.9,140.9,140.7,140.5,140.4,139.9,139.3$, $135.9,133.0,132.1,130.5,126.2,126.1,125.8,121.8,121.5,121.3,120.2,120.1,119.7$, 
$115.6,114.7,92.5,89.5,89.2,71.3,70.9,70.1,69.7,67.5,55.4,55.2,40.2,40.1,31.7,25.9$, 23.1, 23.0, 19.3, 13.9, 13.8. $\mathrm{MS}(\mathrm{FAB}) \mathrm{m} / \mathrm{z} 941\left(\mathrm{M}^{+}\right)$.

1-[2-(2-Butoxyethoxy)ethoxy]-4-(2'-bromo-2-terfluorenylethynyl)benzene 11d. To a $100-\mathrm{mL}$ round bottom flask containing the yellow viscous liquid 1-[2-(2butoxyethoxy)ethoxy]-4-(2-terfluorenylethynyl)benzene $(0.28 \mathrm{~g}, 0.26 \mathrm{mmol})$ in $30 \mathrm{~mL}$ $\mathrm{CH}_{2} \mathrm{Cl}_{2}$ was added NBS ( $46 \mathrm{mg}, 0.26 \mathrm{mmol}$ ), the mixture was allowed to reflex overnight. After evaporating the solvent, the residue was purified by silica gel flash column chromatography using $\mathrm{CH}_{2} \mathrm{Cl}_{2}$ as eluent to afford $0.27 \mathrm{~g}(90 \%)$ of yellow liquid. ${ }^{1} \mathrm{H} \mathrm{NMR}$ $\left(270 \mathrm{MHz}, \mathrm{CHCl}_{3}, \delta\right) 7.65-7.83(\mathrm{~m}, 14 \mathrm{H}), 7.48-7.51(\mathrm{~m}, 5 \mathrm{H}), 6.90(\mathrm{~d}, J=8.91 \mathrm{~Hz}, 2 \mathrm{H})$, $4.14(\mathrm{t}, J=4.0 \mathrm{~Hz}, 2 \mathrm{H}), 3.87(\mathrm{t}, J=6.0 \mathrm{~Hz}, 2 \mathrm{H}), 3.72(\mathrm{t}, J=4.0 \mathrm{~Hz}, 2 \mathrm{H}), 3.62(\mathrm{t}, J=6.0 \mathrm{~Hz}$, 2H), $3.47(\mathrm{t}, J=8.0 \mathrm{~Hz}, 2 \mathrm{H}), 1.93-2.07(\mathrm{~m}, 12 \mathrm{H}), 1.54-1.58(\mathrm{~m}, 2 \mathrm{H}), 1.32-1.38(\mathrm{~m}, 2 \mathrm{H})$, 1.06-1.16 (m, 12H), $0.91(\mathrm{t}, J=7.56 \mathrm{~Hz}, 3 \mathrm{H}), 0.68-0.74(\mathrm{~m}, 30 \mathrm{H}) .{ }^{13} \mathrm{C} \mathrm{NMR}(67.8 \mathrm{MHz}$, $\left.\mathrm{CDCl}_{3}, \delta\right) 158.7,153.1,151.6,151.3,150.9,150.8,140.6,140.2,139.9,139.0,132.8,130.6$ $126.7,126.1,125.7,121.3,120.9,119.9,114.6,114.2,110.6,89.5,89.2,71.2,70.9,70.1$, $69.7,67.5,55.5,55.3,55.2,55.1,40.2,31.8,26.2,23.2,23.1,19.4,14.0 . \mathrm{MS}(\mathrm{FAB}) \mathrm{m} / \mathrm{z}$ $1170.7\left(\mathrm{M}^{+}\right)$.

1-[2-(2-Butoxyethoxy)ethoxy]-4-(5-iodo-5'-bithienylethynyl)benzene 11e. The coupling procedure for DA-(2) was followed using 2 (1.43 g, $5.45 \mathrm{mmol})$, 5,5'-diiodo-2,2'bithiophene (3.48 g, $8.32 \mathrm{mmol}), \mathrm{Pd}\left(\mathrm{PPh}_{3}\right)_{2} \mathrm{Cl}_{2}(0.15 \mathrm{~g}, 0.21 \mathrm{mmol}), \mathrm{CuI}(20 \mathrm{mg}, 0.11$ mmol) and triethylamine $(10 \mathrm{~mL})$ under $\mathrm{N}_{2}$ in dry THF. The crude product was purified by silica-gel column chromatography using $\mathrm{CH}_{2} \mathrm{Cl}_{2}$ as eluent to afford 11e as a yellow viscous liquid of $2.8 \mathrm{~g}\left(92 \%\right.$ yield). ${ }^{1} \mathrm{H} \mathrm{NMR}\left(400 \mathrm{MHz}, \mathrm{CHCl}_{3}, \delta\right) 7.41(\mathrm{~d}, J=8.10 \mathrm{~Hz}, 2 \mathrm{H}), 7.13$ $(\mathrm{d}, J=3.78 \mathrm{~Hz}, 2 \mathrm{H}), 7.09$ (d, $J=3.78 \mathrm{~Hz}, 2 \mathrm{H}), 6.97(\mathrm{~d}, J=3.78 \mathrm{~Hz}, 2 \mathrm{H}), 6.88(\mathrm{~d}, J=7.83$ 
$\mathrm{Hz}, 2 \mathrm{H}), 6.82(\mathrm{~d}, J=3.78 \mathrm{~Hz}, 2 \mathrm{H}), 4.13(\mathrm{t}, J=4.05 \mathrm{~Hz}, 2 \mathrm{H}), 3.76(\mathrm{t}, J=4.05 \mathrm{~Hz}, 2 \mathrm{H}), 3.69$ $(\mathrm{t}, J=4.05 \mathrm{~Hz}, 2 \mathrm{H}), 3.60(\mathrm{t}, J=4.05 \mathrm{~Hz}, 2 \mathrm{H}), 3.45(\mathrm{t}, J=5.40 \mathrm{~Hz}, 2 \mathrm{H}), 1.53-1.62(\mathrm{~m}, 2 \mathrm{H})$, 1.31-1.39 (m, 2H), $0.90(\mathrm{t}, J=7.29 \mathrm{~Hz}, 3 \mathrm{H}) .{ }^{13} \mathrm{C} \mathrm{NMR}\left(67.8 \mathrm{MHz}, \mathrm{CDCl}_{3}, \delta\right)$ 158.9, 142.5, $137.5,136.8,132.7,132.0,125.2,123.7,122.8,114.7,114.6,94.5,81.1,72.4,71.6,70.8$, 70.0, 69.5, 67.4, 31.7, 19.3, 14.0. $\mathrm{MS}(\mathrm{FAB}) \mathrm{m} / \mathrm{z} 552.2\left(\mathrm{M}^{+}\right)$.

1-[2-(2-Butoxyethoxy)ethoxy]-4-(2-iodo-5”-terthienylethynyl)benzene $11 f$ The coupling procedure for DA-(2) was followed using 2 (0.26 g, $0.99 \mathrm{mmol})$, 2,5'”-diiodo5,2',5',2' '-terthiophene (0.7 g, $1.49 \mathrm{mmol}), \mathrm{Pd}\left(\mathrm{PPh}_{3}\right)_{2} \mathrm{Cl}_{2}$ (28.1 mg, $\left.0.04 \mathrm{mmol}\right), \mathrm{CuI}(3.8$ $\mathrm{mg}, 0.02 \mathrm{mmol}$ ) and triethylamine $(5 \mathrm{~mL})$ under $\mathrm{N}_{2}$ in dry THF. The crude product was purified by silica-gel column chromatography using $\mathrm{CH}_{2} \mathrm{Cl}_{2}$ as eluent to afford $\mathbf{1 1 f}$ as a yellow viscous liquid of $0.37 \mathrm{~g}(58 \%$ yield $) .{ }^{1} \mathrm{H} \mathrm{NMR}\left(400 \mathrm{MHz}, \mathrm{CDCl}_{3}, \delta\right) 7.42(\mathrm{~d}, J=$ $8.91 \mathrm{~Hz}), 7.11-7.16(\mathrm{~m}, 2 \mathrm{H}), 7.01-7.06(\mathrm{~m}, 3 \mathrm{H}), 6.91(\mathrm{~d}, J=8.91 \mathrm{~Hz}, 2 \mathrm{H}), 6.83(\mathrm{~d}, J=3.78$ $\mathrm{Hz}, 2 \mathrm{H}), 4.14(\mathrm{t}, J=3.51 \mathrm{~Hz}, 2 \mathrm{H}), 3.86(\mathrm{t}, J=4.59 \mathrm{~Hz}, 2 \mathrm{H}), 3.71(\mathrm{t}, J=5.40 \mathrm{~Hz}, 2 \mathrm{H}), 3.62$ $(\mathrm{t}, J=5.40 \mathrm{~Hz} 2 \mathrm{H}), 3.46(\mathrm{t}, J=6.75 \mathrm{~Hz} 2 \mathrm{H}), 1.39-1.41(\mathrm{~m}, 2 \mathrm{H}), 0.91(\mathrm{t}, J=7.29 \mathrm{~Hz}, 3 \mathrm{H})$.

${ }^{13} \mathrm{C}$ NMR $\left(67.8 \mathrm{MHz}, \mathrm{CDCl}_{3}, \delta\right)$ 158.9, 142.6, 137.6, 137.5, 135.9, 135.2, 132.7, 132.2, $125.0,124.7,124.5,124.4,123.5,122.6,114.8,114.6,94.5,81.3,72.2,71.2,70.9,70.1$, 69.6, 67.5, 31.7, 19.3, 14.0. MS (FAB) $\mathrm{m} / \mathrm{z} 634.1\left(\mathrm{M}^{+}\right)$.

1-[2-(2-Butoxyethoxy)ethoxy]-4-(4-trimethylsilylethynylphenylethynyl)benzene 12a. The coupling procedure for 2 was followed using 11a $(0.89 \mathrm{~g}, 0.19 \mathrm{mmol})$, (trimethylsilyl)acetylene (0.38 g, $0.39 \mathrm{mmol}), \mathrm{Pd}\left(\mathrm{PPh}_{3}\right)_{2} \mathrm{Cl}_{2}(0.05 \mathrm{~g}, 0.08 \mathrm{mmol}), \mathrm{CuI}(7.3$ $\mathrm{mg}, 0.04 \mathrm{mmol})$ and triethylamine $(10 \mathrm{~mL})$ under $\mathrm{N}_{2}$ in dry THF. The crude product was purified by silica-gel column chromatography using $\mathrm{CH}_{2} \mathrm{Cl}_{2}$ as eluent to afford the yellow solid of $0.83 \mathrm{~g}$ (92\% yield). .The deprotection procedure for 2 was followed using the 
yellow solid $(0.43 \mathrm{~g}, 0.99 \mathrm{mmol})$ and potassium carbonate $(0.3 \mathrm{~g}, 2.17 \mathrm{mmol})$ in $\mathrm{CHCl}_{3}(20$ $\mathrm{mL})$ and methanol $(20 \mathrm{~mL})$. The reaction mixture was stirred $3 \mathrm{~h}$ at room temperature. The crude product was purified by silica-gel column chromatography using $\mathrm{CH}_{2} \mathrm{Cl}_{2}$ as eluent to afford 12a as a yellow viscous liquid of $0.64 \mathrm{mg}$ (99\% yield). ${ }^{1} \mathrm{H} \mathrm{NMR}\left(270 \mathrm{MHz}, \mathrm{CDCl}_{3}\right.$,

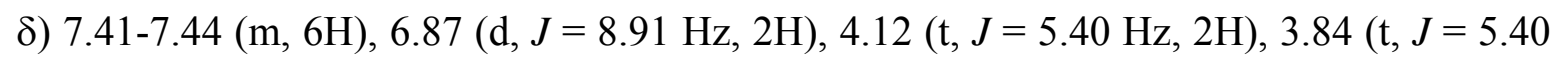
$\mathrm{Hz}, 2 \mathrm{H}), 3.70(\mathrm{t}, J=4.05 \mathrm{~Hz}, 2 \mathrm{H}), 3.58(\mathrm{t}, J=5.40 \mathrm{~Hz}, 2 \mathrm{H}), 3.45(\mathrm{t}, J=6.75 \mathrm{~Hz}, 2 \mathrm{H}), 3.15$ $(\mathrm{s}, 1 \mathrm{H}), 1.53-1.58(\mathrm{~m}, 2 \mathrm{H}), 1.30-1.39(\mathrm{~m}, 2 \mathrm{H}), 0.90(\mathrm{t}, J=7.29 \mathrm{~Hz}, 3 \mathrm{H}) .{ }^{13} \mathrm{C} \mathrm{NMR}(67.8$ $\left.\mathrm{MHz}, \mathrm{CDCl}_{3}, \delta\right) 158.6,132.6,131.5,130.8,123.7,121.1,114.6,114.3,91.3,87.3,83.0$, 78.9, 70.5, 69.7, 69.2, 67.1, 31.5, 19.1, 13.7. MS (FAB) $\mathrm{m} / \mathrm{z} 362.3\left(\mathrm{M}^{+}\right)$.

\section{1-[2-(2-Butoxyethoxy)ethoxy]-4-(7-trimethylsilylethynyl-2-fluorenylethynyl)benzene}

12b The coupling procedure for 2 was followed using $11 \mathbf{b}$ (0.89 g, $0.19 \mathrm{mmol})$, (trimethylsilyl)acetylene (0.38 g, $0.39 \mathrm{mmol}), \mathrm{Pd}\left(\mathrm{PPh}_{3}\right)_{2} \mathrm{Cl}_{2}(0.05 \mathrm{~g}, 0.08 \mathrm{mmol}), \mathrm{CuI}(7.3$ $\mathrm{mg}, 0.04 \mathrm{mmol})$ and triethylamine $(10 \mathrm{~mL})$ under $\mathrm{N}_{2}$ in dry THF. The crude product was purified by silica-gel column chromatography using $\mathrm{CH}_{2} \mathrm{Cl}_{2}$ as eluent to afford a yellow solid of $0.83 \mathrm{~g}$ (92\% yield). The deprotection procedure for 2 was followed using the yellow solid $(0.18 \mathrm{~g}, 0.28 \mathrm{mmol})$ and potassium carbonate $(48 \mathrm{mg}, 0.35 \mathrm{mmol})$ in $\mathrm{CH}_{2} \mathrm{Cl}_{2}$ $(20 \mathrm{~mL})$ and methanol $(20 \mathrm{~mL})$. The reaction mixture was stirred $2 \mathrm{~h}$ at room temperature. The crude product was purified by silica-gel column chromatography using $\mathrm{CH}_{2} \mathrm{Cl}_{2}$ as eluent to afford 12b as a yellow viscous liquid of $0.15 \mathrm{~g}$ (92\% yield). ${ }^{1} \mathrm{H}$ NMR (400 MHz, $\left.\mathrm{CDCl}_{3}, \delta\right)$ 7.56-7.64 (m, 2H), 7.45-7.49 (m, 2H), $6.89(\mathrm{~d}, J=8.64 \mathrm{~Hz}, 2 \mathrm{H}), 4.15(\mathrm{t}, J=6.00$ $\mathrm{Hz}, 2 \mathrm{H}), 3.86(\mathrm{t}, J=8.00 \mathrm{~Hz}, 2 \mathrm{H}), 3.76(\mathrm{t}, J=12.0 \mathrm{~Hz}, 2 \mathrm{H}), 3.60(\mathrm{t}, J=6.00 \mathrm{~Hz}, 2 \mathrm{H}), 3.47$ $(\mathrm{t}, J=16.0 \mathrm{~Hz}, 2 \mathrm{H}), 3.13(\mathrm{~s}, 1 \mathrm{H}), 1.92-1.98(\mathrm{~m}, 4 \mathrm{H}), 1.51-1.66(\mathrm{~m}, 2 \mathrm{H}), 1.28-1.42(\mathrm{~m}, 2 \mathrm{H})$, $1.02-1.11(\mathrm{~m}, 4 \mathrm{H}), 0.88-0.93(\mathrm{~m}, 4 \mathrm{H}), 0.63-0.68(\mathrm{~m}, 6 \mathrm{H}), 0.55-0.56(\mathrm{~m}, 4 \mathrm{H}) .{ }^{13} \mathrm{C} \mathrm{NMR}$ 
(67.8 MHz, $\left.\mathrm{CDCl}_{3}, \delta\right)$ 158.7, 150.8, 150.7, 141.0, 140.0, 132.8, 131.1, 130.4, 126.3, 125.6, $122.3,120.4,119.9,119.7,115.4,114.6,89.7,89.0,84.5,71.2,70.8,70.0,69.6,67.4,55.1$, 40.1, 31.7, 25.9, 23.0, 19.3, 13.9. MS (FAB) $\mathrm{m} / \mathrm{z} 562.4\left(\mathrm{M}^{+}\right)$.

\section{1-[2-(2-Butoxyethoxy)ethoxy]-4-(2'-trimethylsilylethynyl-2-bifluorenylethynyl)-}

benzene 12c. The coupling procedure for 2 was followed using 11c $(0.89 \mathrm{~g}, 0.19 \mathrm{mmol})$, (trimethylsilyl)acetylene (0.38 g, $0.39 \mathrm{mmol}), \mathrm{Pd}\left(\mathrm{PPh}_{3}\right)_{2} \mathrm{Cl}_{2}(0.05 \mathrm{~g}, 0.08 \mathrm{mmol}), \mathrm{CuI}(7.3$ $\mathrm{mg}, 0.04 \mathrm{mmol})$ and triethylamine $(10 \mathrm{~mL})$ under $\mathrm{N}_{2}$ in dry THF. The crude product was purified by silica-gel column chromatography using $\mathrm{CH}_{2} \mathrm{Cl}_{2}$ as eluent to afford a yellow solid of $0.83 \mathrm{~g}$ ( $92 \%$ yield). The deprotection procedure for 2 was followed using the yellow solid $(0.91 \mathrm{~g}, 1.00 \mathrm{mmol})$ and potassium carbonate $(0.3 \mathrm{~g}, 2.17 \mathrm{mmol})$ in $\mathrm{CHCl}_{3}(20$ $\mathrm{mL})$ and methanol $(20 \mathrm{~mL})$. The reaction mixture was stirred $3 \mathrm{~h}$ at room temperature. The crude product was purified by silica-gel column chromatography using $\mathrm{CH}_{2} \mathrm{Cl}_{2}$ as eluent to afford 12c as a yellow viscous liquid of $0.64 \mathrm{mg}$ (99\% yield). ${ }^{1} \mathrm{H}$ NMR $\left(400 \mathrm{MHz}, \mathrm{CDCl}_{3}\right.$, б) $7.77(\mathrm{~d}, J=7.60 \mathrm{~Hz}, 2 \mathrm{H}), 7.62-7.71(\mathrm{~m}, 6 \mathrm{H}), 7.48-7.54(\mathrm{~m}, 6 \mathrm{H}), 6.91(\mathrm{~d}, J=8.80 \mathrm{~Hz}$, 2H), 4.16 (t, $J=4.80 \mathrm{~Hz}, 2 \mathrm{H}), 3.88(\mathrm{t}, J=4.80 \mathrm{~Hz}, 2 \mathrm{H}), 3.72(\mathrm{t}, J=5.00 \mathrm{~Hz}, 2 \mathrm{H}), 3.62(\mathrm{t}, J$ $=4.80 \mathrm{~Hz}, 2 \mathrm{H}), 3.48(\mathrm{t}, J=6.80 \mathrm{~Hz}, 2 \mathrm{H}), 2.02-2.04(\mathrm{~m}, 8 \mathrm{H}), 1.56-1.60(\mathrm{~m}, 2 \mathrm{H}), 1.34-1.40$ (m, 2H), 1.08-1.34 (m, 8H), $0.92(\mathrm{t}, J=7.60 \mathrm{~Hz}, 3 \mathrm{H}), 0.66-0.71(\mathrm{~m}, 20 \mathrm{H}) .{ }^{13} \mathrm{C}$ NMR $(100$ $\left.\mathrm{MHz}, \mathrm{CDCl}_{3}, \delta\right) 158.8,151.8,151.7,151.0,150.9,141.5,140.8,140.6,140.5,139.8,139.5$, $132.9,131.2,130.5,128.7,126.2,126.1,125.8,125.1,121.7,121.3,120.3,120.2,119.7$, 119.6, 119.5, 115.6, 114.6, 89.5, 89.2, 71.2, 70.9, 70.1, 69.6, 67.4, 55.1, 40.2, 40.1, 40.0, 31.6, 31.4, 31.3, 25.9, 23.0, 19.2, 13.9, 13.8. MS (FAB) $\mathrm{m} / \mathrm{z} 839.3\left(\mathrm{M}^{+}\right)$.

\section{1-[2-(2-Butoxyethoxy)ethoxy]-4-(2'-trimethylsilylethynyl-2-terfluorenylethynyl)-}

benzene 12d. The coupling procedure for 2 was followed using 11d ( $80 \mathrm{mg}, 0.07 \mathrm{mmol})$, 
(trimethylsilyl)acetylene (13.4 mg, $0.14 \mathrm{mmol}), \mathrm{PdCl}_{2}(0.5 \mathrm{mg}, 0.003 \mathrm{mmol}), \mathrm{CuI}(0.26 \mathrm{mg}$, $0.0001 \mathrm{mmol}), \mathrm{PPh}_{3}(0.72 \mathrm{mg}, 0.003 \mathrm{mmol})$ and triethylamine $(5 \mathrm{~mL})$ under $\mathrm{N}_{2}$ in dry THF. The crude product was purified by silica-gel column chromatography using $\mathrm{CH}_{2} \mathrm{Cl}_{2}$ as eluent to afford a yellow solid of $73 \mathrm{mg}$ (90\% yield). The deprotection procedure for 2 was followed using the yellow solid $(73 \mathrm{mg}, 0.06 \mathrm{mmol})$ and potassium carbonate $(10.2 \mathrm{mg}$, $0.07 \mathrm{mmol})$ in $\mathrm{CHCl}_{3}(20 \mathrm{~mL})$ and methanol $(20 \mathrm{~mL})$. The reaction mixture was stirred $3 \mathrm{~h}$ at room temperature. The crude product was purified by silica-gel column chromatography using $\mathrm{CH}_{2} \mathrm{Cl}_{2}$ as eluent to afford 12d as a yellow viscous liquid of $59 \mathrm{mg}$ (85\% yield). ${ }^{1} \mathrm{H}$ NMR (270 MHz, $\left.\mathrm{CDCl}_{3}, \delta\right)$ 7.82-7.65 (m, 15H), 7.51-7.48 (m, 5H), $6.90(\mathrm{~d}, J=8.10 \mathrm{~Hz}$, 2H), $4.16(\mathrm{t}, J=4.80 \mathrm{~Hz}, 2 \mathrm{H}), 3.88(\mathrm{t}, J=4.80 \mathrm{~Hz}, 2 \mathrm{H}), 3.72(\mathrm{t}, J=5.00 \mathrm{~Hz}, 2 \mathrm{H}), 3.62(\mathrm{t}, J$ $=4.80 \mathrm{~Hz}, 2 \mathrm{H}), 3.47(\mathrm{t}, J=6.80 \mathrm{~Hz}, 2 \mathrm{H}), 3.15(\mathrm{~s}, 1 \mathrm{H}), 2.02-2.04(\mathrm{~m}, 12 \mathrm{H}),, 1.56-1.60(\mathrm{~m}$, 2H), $1.34-1.40(\mathrm{~m}, 2 \mathrm{H}), 1.10-1.33(\mathrm{~m}, 12 \mathrm{H}), 0.91(\mathrm{t}, J=7.29 \mathrm{~Hz}, 3 \mathrm{H}), 0.67-0.74(\mathrm{~m}, 30 \mathrm{H})$. ${ }^{13} \mathrm{C}$ NMR $\left(67.8 \mathrm{MHz}, \mathrm{CDCl}_{3}, \delta\right)$ 158.6, 151.6, 151.3, 150.9, 150.8, 141.4, 140.9, 140.6, $140.3,140.2,140.1,140.0,139.9,139.8,139.6,139.3,132.9,130.4,126.7,126.0,125.9$, $125.7,122.8,121.6,121.3,121.2,120.2,120.1,119.9,115.6,114.6,89.4,89.2,71.3,70.9$, $69.6,67.5,55.5,55.3,55.2,55.1,40.3,31.8,26.2,26.1,23.2,19.4,14.0,13.9$. HRMS (MALDI-TOF) $\mathrm{m} / \mathrm{z}$ calcd for $\mathrm{C}_{81} \mathrm{H}_{94} \mathrm{O}_{3}, 1114.7197$. Found: 1114.7210 [M] $]^{+}$

\section{1-[2-(2-Butoxyethoxy)ethoxy]-4-(5-trimethylsilylethynyl-5'-bithienylethynyl)benzene}

12e The coupling procedure for 2 was followed using 11e $(0.13 \mathrm{~g}, 0.24 \mathrm{mmol})$, (trimethylsilyl)acetylene (46.3 mg, $0.47 \mathrm{mmol}), \mathrm{Pd}\left(\mathrm{PPh}_{3}\right)_{2} \mathrm{Cl}_{2}(6.5 \mathrm{mg}, 0.009 \mathrm{mmol}), \mathrm{CuI}$ (0.9 mg, $0.004 \mathrm{mmol})$ and triethylamine $(5 \mathrm{~mL})$ under $\mathrm{N}_{2}$ in dry THF. The crude product was purified by silica-gel column chromatography using $\mathrm{CH}_{2} \mathrm{Cl}_{2}$ as eluent to afford a yellow solid of $83 \mathrm{mg}$ (68\% yield). The deprotection procedure for 2 was followed using 
the yellow solid $(81.2 \mathrm{mg}, 0.16 \mathrm{mmol})$ and potassium carbonate $(26 \mathrm{mg}, 0.19 \mathrm{mmol})$ in $\mathrm{CHCl}_{3}(10 \mathrm{~mL})$ and methanol $(10 \mathrm{~mL})$. The reaction mixture was stirred $3 \mathrm{~h}$ at room temperature. The crude product was purified by silica-gel column chromatography using $\mathrm{CH}_{2} \mathrm{Cl}_{2}$ as eluent to afford $12 \mathrm{e}$ as a yellow viscous liquid of $70 \mathrm{mg}(100 \%$ yield $) .{ }^{1} \mathrm{H} \mathrm{NMR}$ $\left(270 \mathrm{MHz}, \mathrm{CDCl}_{3}, \delta\right) 7.41(\mathrm{~d}, J=8.91 \mathrm{~Hz}, 2 \mathrm{H}), 7.15(\mathrm{~d}, J=3.78 \mathrm{~Hz}, 2 \mathrm{H}), 7.11(\mathrm{~d}, J=3.78$ $\mathrm{Hz}, 2 \mathrm{H}), 7.01(\mathrm{~d}, J=4.05 \mathrm{~Hz}, 2 \mathrm{H}), 6.88(\mathrm{~d}, J=8.64 \mathrm{~Hz}, 2 \mathrm{H}), 4.14(\mathrm{t}, J=5.40 \mathrm{~Hz}, 2 \mathrm{H})$, $3.87-3.84(\mathrm{t}, J=4.05 \mathrm{~Hz}, 2 \mathrm{H}), 3.71(\mathrm{t}, J=4.05 \mathrm{~Hz}, 2 \mathrm{H}), 3.60(\mathrm{t}, J=4.05 \mathrm{~Hz}, 2 \mathrm{H}), 3.46(\mathrm{t}, J$ $=6.75 \mathrm{~Hz}, 2 \mathrm{H}), 3.40(\mathrm{~s}, 1 \mathrm{H}) 1.54-1.58(\mathrm{~m}, 2 \mathrm{H}), 1.24-1.39(\mathrm{~m}, 2 \mathrm{H}), 0.90(\mathrm{t}, J=7.29 \mathrm{~Hz}$,

3H). ${ }^{13} \mathrm{C} \mathrm{NMR}\left(67.8 \mathrm{MHz}, \mathrm{CDCl}_{3}, \delta\right) 158.9,138.3,137.1,133.8,132.7,132.1,124.0$, $123.4,123.2,120.9,114.7,114.6,94.6,82.5,81.1,71.2,70.9,70.0,69.6,67.5,31.7,19.3$, 14.0. $\mathrm{MS}(\mathrm{FAB}) \mathrm{m} / \mathrm{z} 450.1\left(\mathrm{M}^{+}\right)$.

\section{1-[2-(2-Butoxyethoxy)ethoxy]-4-(2-trimethylsilylethynyl-5’'-terthienylethynyl)benzene}

12f The coupling procedure for 2 was followed using $11 f(0.3 \mathrm{~g}, 0.47 \mathrm{mmol})$, (trimethylsilyl)acetylene (93 mg, $0.95 \mathrm{mmol}), \mathrm{Pd}\left(\mathrm{PPh}_{3}\right)_{2} \mathrm{Cl}_{2}(13.3 \mathrm{mg}, 0.02 \mathrm{mmol}), \mathrm{CuI}(1.8$ $\mathrm{mg}, 0.009 \mathrm{mmol})$ and triethylamine $(5 \mathrm{~mL})$ under $\mathrm{N}_{2}$ in dry THF. The crude product was purified by silica-gel column chromatography using $\mathrm{CH}_{2} \mathrm{Cl}_{2}$ as eluent to afford as a yellow solid of $0.25 \mathrm{~g}$ (87\% yield). The deprotection procedure for 2 was followed using the yellow solid $(0.25 \mathrm{~g}, 0.41 \mathrm{mmol})$ and potassium carbonate $(65.5 \mathrm{mg}, 0.47 \mathrm{mmol})$ in $\mathrm{CHCl}_{3}$ $(20 \mathrm{~mL})$ and methanol $(20 \mathrm{~mL})$. The reaction mixture was stirred $3 \mathrm{~h}$ at room temperature. The crude product was purified by silica-gel column chromatography using $\mathrm{CH}_{2} \mathrm{Cl}_{2}$ as eluent to afford $12 f$ as a yellow viscous liquid of $0.20 \mathrm{~g}$ (92\% yield). ${ }^{1} \mathrm{H}$ NMR (400 MHz, $\left.\mathrm{CDCl}_{3}, \delta\right) 7.41(\mathrm{~d}, J=9.20 \mathrm{~Hz}, 2 \mathrm{H}), 7.13(\mathrm{~d}, J=4.00 \mathrm{~Hz}, 2 \mathrm{H}), 7.09(\mathrm{~d}, J=4.00 \mathrm{~Hz}, 2 \mathrm{H})$, 6.96-7.03 (m, 4H), $6.86(\mathrm{~d}, J=8.80 \mathrm{~Hz}, 2 \mathrm{H}), 4.11(\mathrm{t}, J=5.20 \mathrm{~Hz}, 2 \mathrm{H}), 3.84(\mathrm{t}, J=4.80 \mathrm{~Hz}$, 
2H), $3.69(\mathrm{t}, J=5.60 \mathrm{~Hz}, 2 \mathrm{H}), 3.59(\mathrm{t}, J=6.4 \mathrm{~Hz}, 2 \mathrm{H}), 3.45(\mathrm{t}, J=6.80 \mathrm{~Hz}, 2 \mathrm{H}), 3.41(\mathrm{~s}$, $1 \mathrm{H}), 1.54-1.58(\mathrm{~m}, 2 \mathrm{H}), 1.32-1.38(\mathrm{~m}, 2 \mathrm{H}), 0.89(\mathrm{t}, J=5.20 \mathrm{~Hz}, 3 \mathrm{H}) .{ }^{13} \mathrm{C} \mathrm{NMR}(100 \mathrm{MHz}$, $\left.\mathrm{CDCl}_{3}, \delta\right) 159.0,138.5,137.5,136.2,135.4,133.9,132.8,132.3,125.0,124.6,123.6,123.1$, $122.6,120.6,114.8,114.6,94.5,82.6,81.2,71.1,70.8,70.0,69.5,67.3,31.5,19.2,13.9$. MS (FAB) $m / z 532.1\left(\mathrm{M}^{+}\right)$.

3,6-Bis(1-(4-iodophenyl)ethynyl)dibenzothiophene sulfone 13a. The coupling procedure for 2 was followed using 8 (0.19 g, $0.70 \mathrm{mmol})$, 1,4-diiodobenzene (0.46 g, $1.39 \mathrm{mmol})$, tris(dibenzylideneacetone)dipalladium (0) (25.8 mg, $0.03 \mathrm{mmol}), \mathrm{CuI}(2.7 \mathrm{mg}, 0.01 \mathrm{mmol})$ triphenylphosphine $(18.8 \mathrm{mg}, 0.07 \mathrm{mmol})$ and triethylamine $(5 \mathrm{~mL})$ under $\mathrm{N}_{2}$ in dry THF. The crude product was purified by silica-gel column chromatography using $\mathrm{CH}_{2} \mathrm{Cl}_{2} / \mathrm{PE}$ (v/v 2:1) as eluent to afford 13a as a yellow solid of $0.36 \mathrm{~g}(75 \%$ yield $) .{ }^{1} \mathrm{H} \mathrm{NMR}(400 \mathrm{MHz}$, $\left.\mathrm{CDCl}_{3}, \delta\right) 7.93(\mathrm{~s}, 2 \mathrm{H}), 7.80(\mathrm{~d}, J=8.00 \mathrm{~Hz}, 2 \mathrm{H}), 7.73(\mathrm{~d}, J=8.00 \mathrm{~Hz}, 4 \mathrm{H}), 7.66(\mathrm{~d}, J=$ $8.00 \mathrm{~Hz}, 2 \mathrm{H}), 7.36(\mathrm{~d}, J=8.00 \mathrm{~Hz}, 4 \mathrm{H}) .{ }^{13} \mathrm{C} \mathrm{NMR}\left(100 \mathrm{MHz}, \mathrm{CDCl}_{3}, \delta\right)$ 137.7, 137.0, 133.6, 133.2, 131.3, 129.2, 124.5, 122.4, 121.5, 95.5, 92.6, 88.8. HRMS (MALDI-TOF) $m / z$ calcd for $\mathrm{C}_{28} \mathrm{H}_{15} \mathrm{I}_{2} \mathrm{O}_{2} \mathrm{~S}, 668.2835$. Found: $668.9217[\mathrm{M}+1]^{+}$.

3,6-Bis[2-(7-iodofluorenyl)ethynyl]dibenzothiophene sulfone $13 b$. The coupling procedure for 2 was followed using 8 (0.95 g, $3.61 \mathrm{mmol})$, 9,9-bis( $n$-butyl)-2,7diiodofluorene $(5.7 \mathrm{~g}, 10.71 \mathrm{mmol}), \mathrm{Pd}\left(\mathrm{PPh}_{3}\right)_{2} \mathrm{Cl}_{2}(0.1 \mathrm{~g}, 0.14 \mathrm{mmol}), \mathrm{CuI}(14 \mathrm{mg}, 0.07$ mmol) and triethylamine $(10 \mathrm{~mL})$ under $\mathrm{N}_{2}$ in dry THF. The crude product was purified by silica-gel column chromatography using $\mathrm{CH}_{2} \mathrm{Cl}_{2} / \mathrm{PE}(\mathrm{v} / \mathrm{v} 2: 1)$ as eluent to afford $\mathbf{1 3 b}$ as a yellow solid of $3.8 \mathrm{~g}$ (100\% yield). ${ }^{1} \mathrm{H} \mathrm{NMR}\left(270 \mathrm{MHz}, \mathrm{CDCl}_{3}, \delta\right) 7.99(\mathrm{~s}, 2 \mathrm{H}), 7.82$ (d, J $=8.10 \mathrm{~Hz}, 2 \mathrm{H}), 7.66-7.72(\mathrm{~m}, 8 \mathrm{H}), 7.51-7.56(\mathrm{~m}, 4 \mathrm{H}), 7.45(\mathrm{~d}, J=8.10 \mathrm{~Hz}, 2 \mathrm{H}), 1.93-1.96$ $(\mathrm{m}, 8 \mathrm{H}), 1.06-1.14(\mathrm{~m}, 4 \mathrm{H}), 0.58-0.72(\mathrm{~m}, 10 \mathrm{H}),{ }^{13} \mathrm{C} \mathrm{NMR}\left(67.8 \mathrm{MHz}, \mathrm{CDCl}_{3}, \delta\right) 153.2$, 
$150.2,141.2,139.6,136.6,136.0,133.3,132.0,131.2,130.9,129.5,126.0,124.3,122.2$, 121.7, 120.7, 119.9, 94.5, 93.6, 88.0, 55.4, 40.1, 25.9, 25.1, 13.9. MS (FAB) $m / z 1067.3$ $\left(\mathrm{M}^{+}\right)$.

3,6-Bis[2'-(2-iodobifluorenyl)ethynyl]dibenzothiophene sulfone 13c. The coupling procedure for 2 was followed using $8(0.2 \mathrm{~g}, 0.76 \mathrm{mmol}), 2,2$ '-diiodo-bis[9,9-di $(n$ butyl)fluorene] ( $2.0 \mathrm{~g}, 2.48 \mathrm{mmol}), \mathrm{Pd}\left(\mathrm{PPh}_{3}\right)_{2} \mathrm{Cl}_{2}(0.02 \mathrm{~g}, 0.03 \mathrm{mmol}), \mathrm{CuI}(3 \mathrm{mg}, 0.02$ mmol) and triethylamine $(10 \mathrm{~mL})$ under $\mathrm{N}_{2}$ in dry THF. The crude product was purified by silica-gel column chromatography using $\mathrm{CH}_{2} \mathrm{Cl}_{2} / \mathrm{PE}(\mathrm{v} / \mathrm{v}$ 2:1) as eluent to afford 13c as a yellow solid of $1.08 \mathrm{~g}$ ( $88 \%$ yield). ${ }^{1} \mathrm{H}$ NMR (400 MHz, $\left.\mathrm{CDCl}_{3}, \delta\right) 8.02(\mathrm{~s}, 2 \mathrm{H}), 7.84$ (d, $J$ $=7.60 \mathrm{~Hz}, 2 \mathrm{H}), 7.73-7.80(\mathrm{~m}, 10 \mathrm{H}), 7.57-7.69(\mathrm{~m}, 14 \mathrm{H}), 7.48(\mathrm{~d}, J=8.00 \mathrm{~Hz}, 2 \mathrm{H}), 1.98-$ $2.07(\mathrm{~m}, 16 \mathrm{H}), 1.08-1.16(\mathrm{~m}, 16 \mathrm{H}), 0.65-0.86(\mathrm{~m}, 40 \mathrm{H}) .{ }^{13} \mathrm{C} \mathrm{NMR}\left(100 \mathrm{MHz}, \mathrm{CDCl}_{3}, \delta\right)$ 153.3, 151.9, 151.2, 150.9, 142.0, 141.0, 140.7, 140.3, 139.5, 139.4, 136.6, 135.9, 133.4, 132.0, 131.3, 131.0, 129.7, 126.3, 126.2, 124.4, 122.3, 121.5, 121.3, 121.2, 120.5, 120.1, $119.9,94.9,92.6,87.8,55.3,55.2,40.2,40.0,25.9,25.8,23.0,22.9,13.8,13.7$. HRMS (MALDI-TOF) $\mathrm{m} / \mathrm{z}$ calcd for $\mathrm{C}_{100} \mathrm{H}_{103} \mathrm{IO}_{2} \mathrm{~S}_{2}, 1622.5801$. Found: $1622.5780[\mathrm{M}+\mathrm{H}]^{+}$.

3,6-Bis[2”-(2-iodoterfluorenyl)ethynyl]dibenzothiophene sulfone 13d The coupling procedure for 2 was followed using 8 (0.18 g, $0.69 \mathrm{mmol}), 2,2$ '- $\operatorname{diiodo}-\operatorname{ter}[9,9-\operatorname{bis}(n-$ butyl)fluorene] (1.51 g, $1.39 \mathrm{mmol})$, tris(dibenzylideneacetone)dipalladium (0) (12.5 mg, $0.014 \mathrm{mmol}), \mathrm{CuI}(2.6 \mathrm{mg}, 0.014 \mathrm{mmol})$, triphenylphosphine $(17.8 \mathrm{mg}, 0.07 \mathrm{mmol})$ and triethylamine $(5 \mathrm{~mL})$ under $\mathrm{N}_{2}$ in dry THF. The crude product was purified by silica-gel column chromatography using $\mathrm{CH}_{2} \mathrm{Cl}_{2} / \mathrm{PE}$ (v/v 2:1) as eluent to afford $\mathbf{1 3 d}$ as a yellow solid of $0.98 \mathrm{~g}$ (66 \% yield). ${ }^{1} \mathrm{H}$ NMR $\left(400 \mathrm{MHz}, \mathrm{CDCl}_{3}, \delta\right) 8.04(\mathrm{~s}, 2 \mathrm{H}), 7.82-7.87$ (m, 6H), 7.65-7.79 (m, 28H), $7.61(\mathrm{~d}, J=7.20 \mathrm{~Hz}, 4 \mathrm{H}), 7.49(\mathrm{~d}, J=8.00 \mathrm{~Hz}, 2 \mathrm{H}), 1.99-2.11(\mathrm{~m}$, 
24H), 1.10-1.19 (m, 24H), 0.67-0.79 (m, 60H), $\left.{ }^{13} \mathrm{C} \mathrm{NMR} \mathrm{(100} \mathrm{MHz,} \mathrm{CDCl}_{3}, \delta\right)$ 153.4, $151.9,151.8,151.2,150.9,142.1,141.3,141.0,140.4,140.3,140.2,140.1,140.0,139.3$, $136.7,135.9,133.4,132.1,131.4,131.1,129.8,126.3,126.2,124.4,122.3,121.4,121.3$, $120.5,120.1,120.0,119.9,95.0,92.5,87.8,55.4,55.3,55.2,40.2,40.1,26.1,26.0,25.9$, 23.1, 23.0, 13.8. HRMS (MALDI-TOF) $\mathrm{m} / \mathrm{z}$ calcd for $\mathrm{C}_{142} \mathrm{H}_{151} \mathrm{I}_{2} \mathrm{O}_{2} \mathrm{~S}, 2174.9563$. Found: $2174.9954[\mathrm{M}+\mathrm{H}]^{+}$.

\section{3-(4-\{1-[2-(2-butoxyethoxy)ethoxy]\}phenylethynylphenylethynyl)-6-[1-(4-iodo-}

phenyl)ethynyl]dibenzothiophene sulfone 14a. The coupling procedure for 2 was followed using 13a $(0.20 \mathrm{~g}, 0.31 \mathrm{mmol}), 2$ (26 mg, $0.10 \mathrm{mmol}), \mathrm{Pd}\left(\mathrm{PPh}_{3}\right)_{2} \mathrm{Cl}_{2}(2.8 \mathrm{mg}$, $0.003 \mathrm{mmol}), \mathrm{CuI}(0.4 \mathrm{mg}, 0.002 \mathrm{mmol})$ and triethylamine $(5 \mathrm{~mL})$ under $\mathrm{N}_{2}$ in dry THF. The crude product was purified by silica-gel column chromatography using $\mathrm{CH}_{2} \mathrm{Cl}_{2} / \mathrm{EtOAc}$ (v/v 100:1) as eluent to afford 4-17a as a yellow solid of $52 \mathrm{mg}\left(65 \%\right.$ yield). ${ }^{1} \mathrm{H} \mathrm{NMR}$ $\left(270 \mathrm{MHz}, \mathrm{CDCl}_{3}, \delta\right) 7.93(\mathrm{~s}, 2 \mathrm{H}), 7.63-7.81(\mathrm{~m}, 7 \mathrm{H}), 7.43-7.51(\mathrm{~m}, 6 \mathrm{H}), 7.27(\mathrm{~d}, J=8.37$ $\mathrm{Hz}, 8 \mathrm{H}), 6.89(\mathrm{~d}, J=8.91 \mathrm{~Hz}, 2 \mathrm{H}), 4.15(\mathrm{t}, J=5.13 \mathrm{~Hz}, 2 \mathrm{H}), 3.86(\mathrm{t}, J=5.13 \mathrm{~Hz}, 2 \mathrm{H}), 3.71$ (t, $J=5.13 \mathrm{~Hz}, 2 \mathrm{H}), 3.60(\mathrm{t}, J=3.78 \mathrm{~Hz}, 2 \mathrm{H}), 3.46(\mathrm{t}, J=6.75 \mathrm{~Hz}, 2 \mathrm{H}), 1.95-2.02(\mathrm{~m}, 8 \mathrm{H})$, 1.34-1.36 (m, 2H), $0.90(\mathrm{t}, J=7.29 \mathrm{~Hz}, 3 \mathrm{H}) .{ }^{13} \mathrm{C} \mathrm{NMR}\left(67.8 \mathrm{MHz}, \mathrm{CDCl}_{3}, \delta\right)$ 159.0, 137.7, $136.9,136.8,133.9,133.5,133.1,133.0,131.6,131.4,131.2,131.1,129.3,129.0,124.5$, $124.4,122.2,121.5,115.0,114.7,95.4,93.3,92.5,92.1,89.0,88.8,87.7,71.3,70.9,70.1$, 69.6, 67.5, 31.8, 19.4, 14.0. HRMS (MALDI-TOF) $\mathrm{m} / \mathrm{z}$ for $\mathrm{C}_{44} \mathrm{H}_{35} \mathrm{IO}_{5} \mathrm{~S}: 806.5[\mathrm{M}+1]^{+}$. 3-(4-\{1-[2-(2-butoxyethoxy)ethoxy]\}phenylethynylphenylethynyl)-6-[2-(7-iodo-

fluorenyl)ethynyl]dibenzothiophene sulfone 14b. The coupling procedure for 2 was followed using 13b $(0.71 \mathrm{~g}, 0.66 \mathrm{mmol}), 2$ (88 mg, $0.34 \mathrm{mmol}), \mathrm{Pd}\left(\mathrm{PPh}_{3}\right)_{2} \mathrm{Cl}_{2}(9.3 \mathrm{mg}, 0.01$ mmol), $\mathrm{CuI}(1.3 \mathrm{mg}, 0.007 \mathrm{mmol})$ and triethylamine $(10 \mathrm{~mL})$ under $\mathrm{N}_{2}$ in dry THF. The 
crude product was purified by silica-gel column chromatography using $\mathrm{CH}_{2} \mathrm{Cl}_{2} / \mathrm{EtoAc}$ (v/v $100: 1)$ as eluent to afford $\mathbf{1 4 b}$ as a yellow solid of $0.34 \mathrm{~g}(60 \%$ yield $) .{ }^{1} \mathrm{H}$ NMR (400 MHz, $\left.\mathrm{CDCl}_{3}, \delta\right) 7.99(\mathrm{~s}, 2 \mathrm{H}), 7.82(\mathrm{~d}, J=8.00 \mathrm{~Hz}, 2 \mathrm{H}), 7.66-7.72(\mathrm{~m}, 8 \mathrm{H}), 7.43-7.57(\mathrm{~m}, 8 \mathrm{H})$, $6.90(\mathrm{~d}, J=9.20 \mathrm{~Hz}, 2 \mathrm{H}), 4.15(\mathrm{t}, J=4.00 \mathrm{~Hz}, 2 \mathrm{H}), 3.87(\mathrm{t}, J=4.00 \mathrm{~Hz}, 2 \mathrm{H}), 3.89(\mathrm{t}, J=$ $6.00 \mathrm{~Hz}, 2 \mathrm{H}), 3.60(\mathrm{t}, J=5.40 \mathrm{~Hz}, 2 \mathrm{H}), 3.44(\mathrm{t}, J=6.75 \mathrm{~Hz}, 2 \mathrm{H}), 1.95-2.02(\mathrm{~m}, 8 \mathrm{H}), 1.54-$ $1.60(\mathrm{~m}, 2 \mathrm{H}), 1.23-1.36(\mathrm{~m}, 2 \mathrm{H}), 1.07-1.12(\mathrm{~m}, 8 \mathrm{H}), 0.90(\mathrm{t}, \mathrm{J}=7.60 \mathrm{~Hz}, 3 \mathrm{H}), 0.66-0.70(\mathrm{~m}$,

8H), 0.55-0.61 (m, 12H). $\left.{ }^{13} \mathrm{C} \mathrm{NMR} \mathrm{(100} \mathrm{MHz,} \mathrm{CDCl}_{3}, \delta\right)$ 158.9, 153.4, 151.2, 151.1, 150.4, $141.8,141.3,140.0,139.8,136.8,136.7,136.6,136.1,133.4,133.0,132.1,131.4,131.1$, $132.1,131.4,131.1,130.7,129.7,129.6,126.1,125.8,124.4,122.7,122.3,121.8,120.8$, $120.5,120.1,120.0,115.4,114.7,94.8,97.6,93.6,90.0,89.0,88.0,87.9,71.3,70.9,70.1$, 69.6, 67.5, 55.4, 55.2, 40.2, 40.1, 31.7, 25.9, 23.0, 19.3, 13.9, 13.8. MS (FAB) $\mathrm{m} / \mathrm{z} 1201.3$ $\left(\mathrm{M}^{+}\right)$.

\section{3-(4-\{1-[2-(2-butoxyethoxy)ethoxy]\}phenylethynylphenylethynyl)-6-[2'-(2-iodo-}

bifluorenyl)ethynyl]dibenzothiophene sulfone 14c. The coupling procedure for 2 was followed using 13c (1.0 g, $0.62 \mathrm{mmol}), 2(82 \mathrm{mg}, 0.31 \mathrm{mmol}), \mathrm{Pd}\left(\mathrm{PPh}_{3}\right)_{2} \mathrm{Cl}_{2}(8.8 \mathrm{mg}, 0.01$ mmol), $\mathrm{CuI}(1.2 \mathrm{mg}, 0.006 \mathrm{mmol})$ and triethylamine $(10 \mathrm{~mL})$ under $\mathrm{N}_{2}$ in dry THF. The crude product was purified by silica-gel column chromatography using $\mathrm{CH}_{2} \mathrm{Cl}_{2} / \mathrm{EtoAc}(\mathrm{v} / \mathrm{v}$ 100:1) as eluent to afford 14c as a yellow solid of $0.46 \mathrm{~g}(61 \%$ yield $) .{ }^{1} \mathrm{H}$ NMR (400 MHz, $\left.\mathrm{CDCl}_{3}, \delta\right) 8.02(\mathrm{~s}, 2 \mathrm{H}), 7.58-7.85(\mathrm{~m}, 24 \mathrm{H}), 7.47-7.53(\mathrm{~m}, 6 \mathrm{H}), 6.90(\mathrm{~d}, J=8.80 \mathrm{~Hz}, 2 \mathrm{H})$, $4.15(\mathrm{t}, J=4.00 \mathrm{~Hz}, 2 \mathrm{H}), 3.87(\mathrm{t}, J=4.00 \mathrm{~Hz}, 2 \mathrm{H}), 3.71(\mathrm{t}, J=5.40 \mathrm{~Hz}, 2 \mathrm{H}), 3.60(\mathrm{t}, J=$ $5.40 \mathrm{~Hz}, 2 \mathrm{H}), 3.47(\mathrm{t}, J=6.00 \mathrm{~Hz}, 2 \mathrm{H}), 1.98-2.07(\mathrm{~m}, 16 \mathrm{H}), 1.55-1.60(\mathrm{~m}, 2 \mathrm{H}), 1.33-1.38$ $(\mathrm{m}, 2 \mathrm{H}), 1.01-1.23(\mathrm{~m}, 16 \mathrm{H}), 0.91(\mathrm{t}, J=7.60 \mathrm{~Hz}, 3 \mathrm{H}), 0.67-0.72(\mathrm{~m}, 40 \mathrm{H}) .{ }^{13} \mathrm{C} \mathrm{NMR}$ $\left(100 \mathrm{MHz}, \mathrm{CDCl}_{3}, \delta\right)$ 159.0, 153.6, 152.2, 152.1, 151.5, 151.2, 142.3, 142.2, 141.4, 141.3, 
142.0, 140.9, 140.7, 140.6, 140.2, 139.8, 139.7, 139.6, 136.9, 136.2, 133.7, 133.2, 132.3, 131.7, 131.3, 130.8, 130.0, 126.6, 126.5, 126.4, 126.1, 124.7, 122.6, 122.1, 121.7, 121.6, $121.5,120.7,120.5,120.4,120.2,120.0,115.8,115.0,95.2,95.1,92.9,89.8,89.4,88.1$, $88.0,71.5,71.2,70.4,69.9,67.7,55.6,55.5,55.4,40.4,40.3,31.9,26.2,23.3,23.2,19.5$, 14.2, 14.1, 14.0. HRMS (MALDI-TOF) $\mathrm{m} / \mathrm{z}$ for $\mathrm{C}_{108} \mathrm{H}_{119} \mathrm{IO}_{5} \mathrm{~S}: 1755.4193[\mathrm{M}]^{+}$.

\section{3-(4-\{1-[2-(2-butoxyethoxy)ethoxy]\}phenylethynylphenylethynyl)-6-[2'-(2-iodo-}

terfluorenyl)ethynyl]dibenzothiophene sulfone 14d. The coupling procedure for $\mathbf{2}$ was followed using $13 d \quad(0.45 \quad \mathrm{~g}, \quad 0.21 \quad \mathrm{mmol}), \quad 2 \quad(21.8 \quad \mathrm{mg}, \quad 0.08 \quad \mathrm{mmol})$, tris(dibenzylideneacetone)dipalladium (0) $(1.52 \mathrm{mg}, 0.002 \mathrm{mmol}), \mathrm{CuI}(0.3 \mathrm{mg}, 0.002$ mmol) triphenylphosphine $(2.17 \mathrm{mg}, 0.008 \mathrm{mmol})$ and triethylamine $(5 \mathrm{~mL})$ under $\mathrm{N}_{2}$ in dry THF. The crude product was purified by silica-gel column chromatography using $\mathrm{CH}_{2} \mathrm{Cl}_{2} / \mathrm{EtoAc}$ (v/v 100:1) as eluent to afford 14d as a yellow solid of $86 \mathrm{mg}$ (45\% yield). ${ }^{1} \mathrm{H}$ NMR $\left(400 \mathrm{MHz}, \mathrm{CDCl}_{3}, \delta\right) 8.04(\mathrm{~s}, 2 \mathrm{H}), 7.7 .60-7.87(\mathrm{~m}, 36 \mathrm{H})$, 7.50-7.54 (m, 6H), 6.92 (d, $J=9.20 \mathrm{~Hz}, 2 \mathrm{H}), 4.17$ (t, $J=5.60 \mathrm{~Hz}, 2 \mathrm{H}), 3.89$ (t, $J=4.40 \mathrm{~Hz}, 2 \mathrm{H}), 3.73$ (t, $J=5.20$ $\mathrm{Hz}, 2 \mathrm{H}), 3.63(\mathrm{t}, J=6.40 \mathrm{~Hz}, 2 \mathrm{H}), 3.48(\mathrm{t}, J=6.80 \mathrm{~Hz}, 2 \mathrm{H}), 2.04-2.11(\mathrm{~m}, 24 \mathrm{H}), 1.56-1.61$ (m, 2H), 1.25-1.38 (m, 2H), 1.10-1.19 (m, 24H), $0.91(\mathrm{t}, J=7.60 \mathrm{~Hz}, 3 \mathrm{H}), 0.69-0.79(\mathrm{~m}$, 60H). $\left.{ }^{13} \mathrm{C} \mathrm{NMR} \mathrm{(100} \mathrm{MHz,} \mathrm{CDCl}_{3}, \delta\right)$ 158.8, 153.4, 151.9, 151.8, 151.2, 151.0, 150.9, $142.1,141.3,141.0,140.7,140.5,140.4,140.3,140.2,140.1,140.0,139.9,139.7,139.3$, $136.6,135.9,134.0,133.9,133.4,133.0,132.1,131.4,131.0,130.5,129.8,126.4$, $126.3,126.2,126.0,125.8,124.4,122.3,121.7,121.3,120.8,120.5,120.2,120.1,120.0$, $119.9,119.7,115.6,114.7,114.6,114.1,114.0,95.0,92.5,89.5,89.2,87.8,81.2,72.9,71.2$, 70.9, 70.1, 69.7, 69.6, 55.3, 55.2, 40.2, 31.7, 29.7, 26.9, 26.1, 26.0, 23.1, 19.2, 13.9, 13.8. HRMS (MALDI-TOF) $\mathrm{m} / \mathrm{z}$ calcd for $\mathrm{C}_{158} \mathrm{H}_{171} \mathrm{I}_{2} \mathrm{O}_{5} \mathrm{~S}, 2308.1920$. Found: 2308.1953 [M] $]^{+}$ 


\section{${ }^{1}$ H NMR spectra of DA(n)s and D-Ar-A(n)s:}
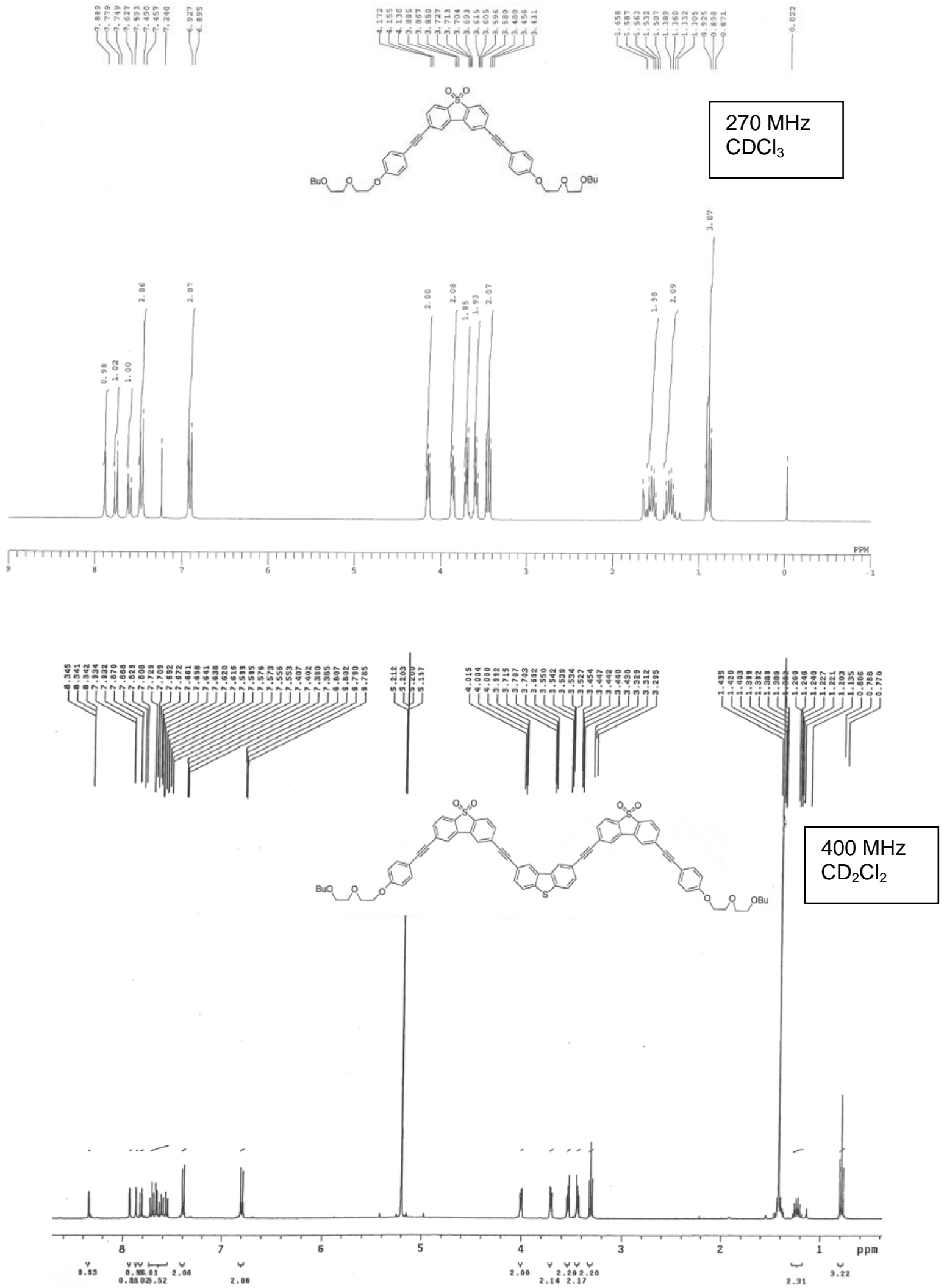
Supporting Information

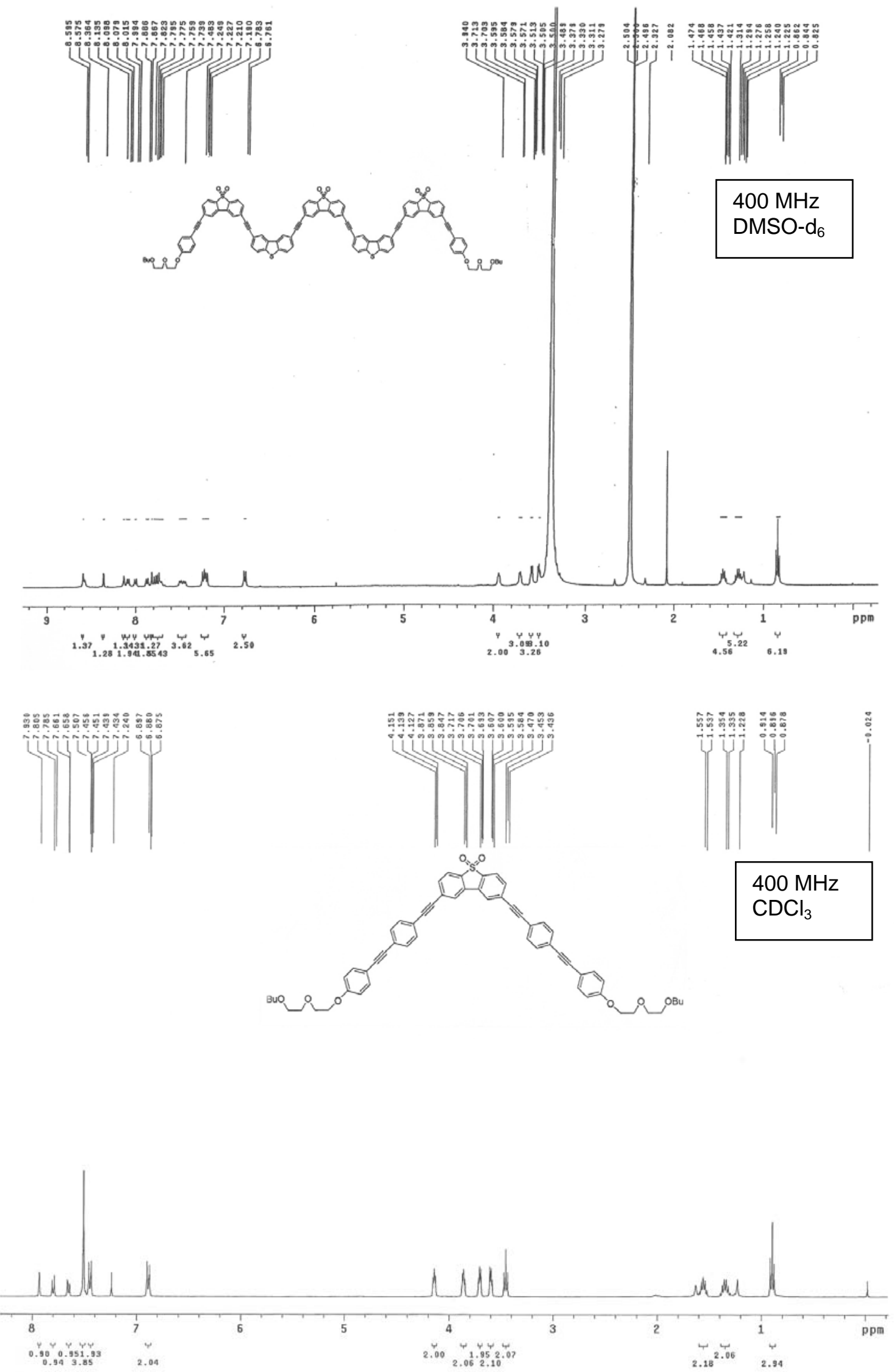


Supporting Information

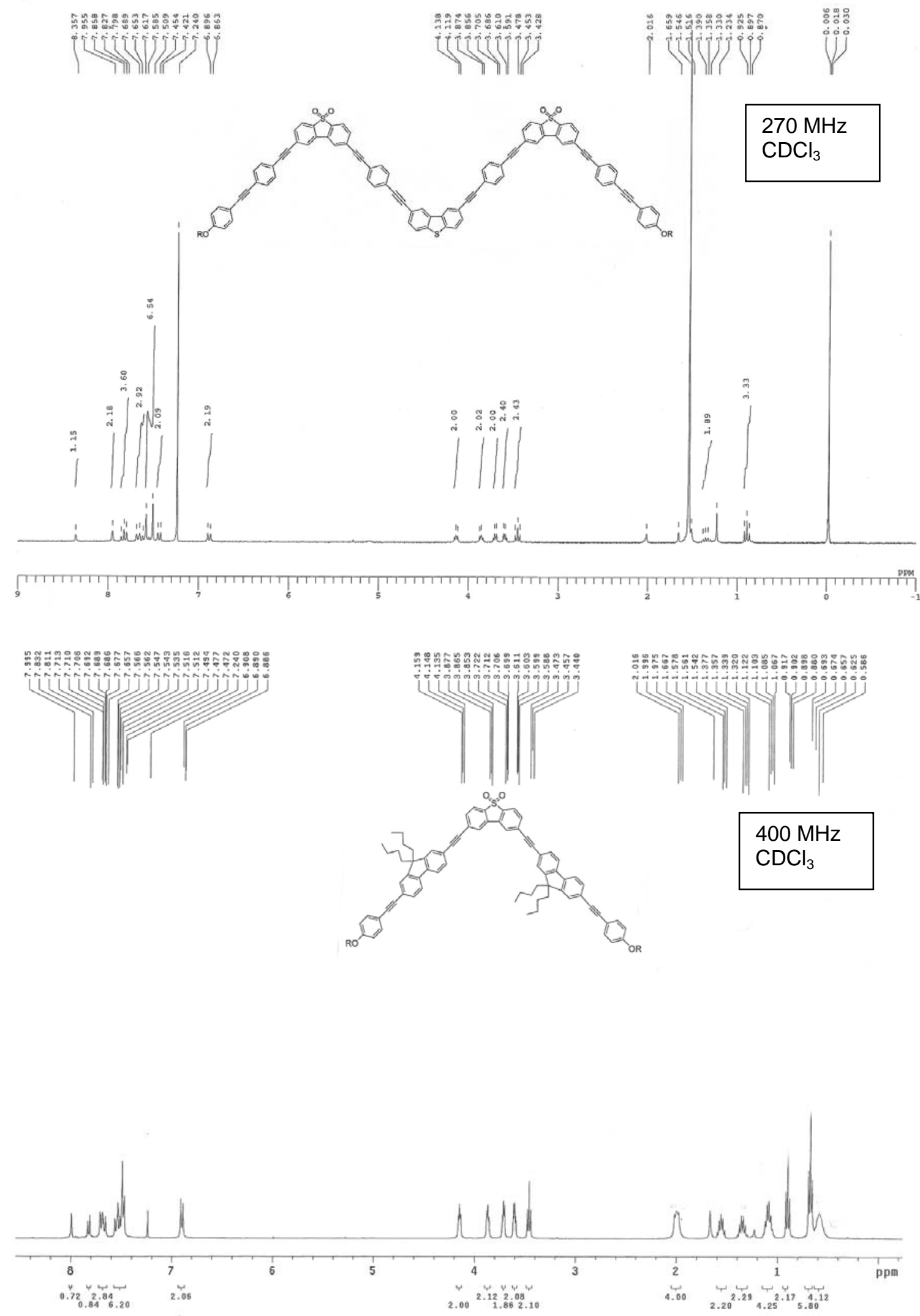



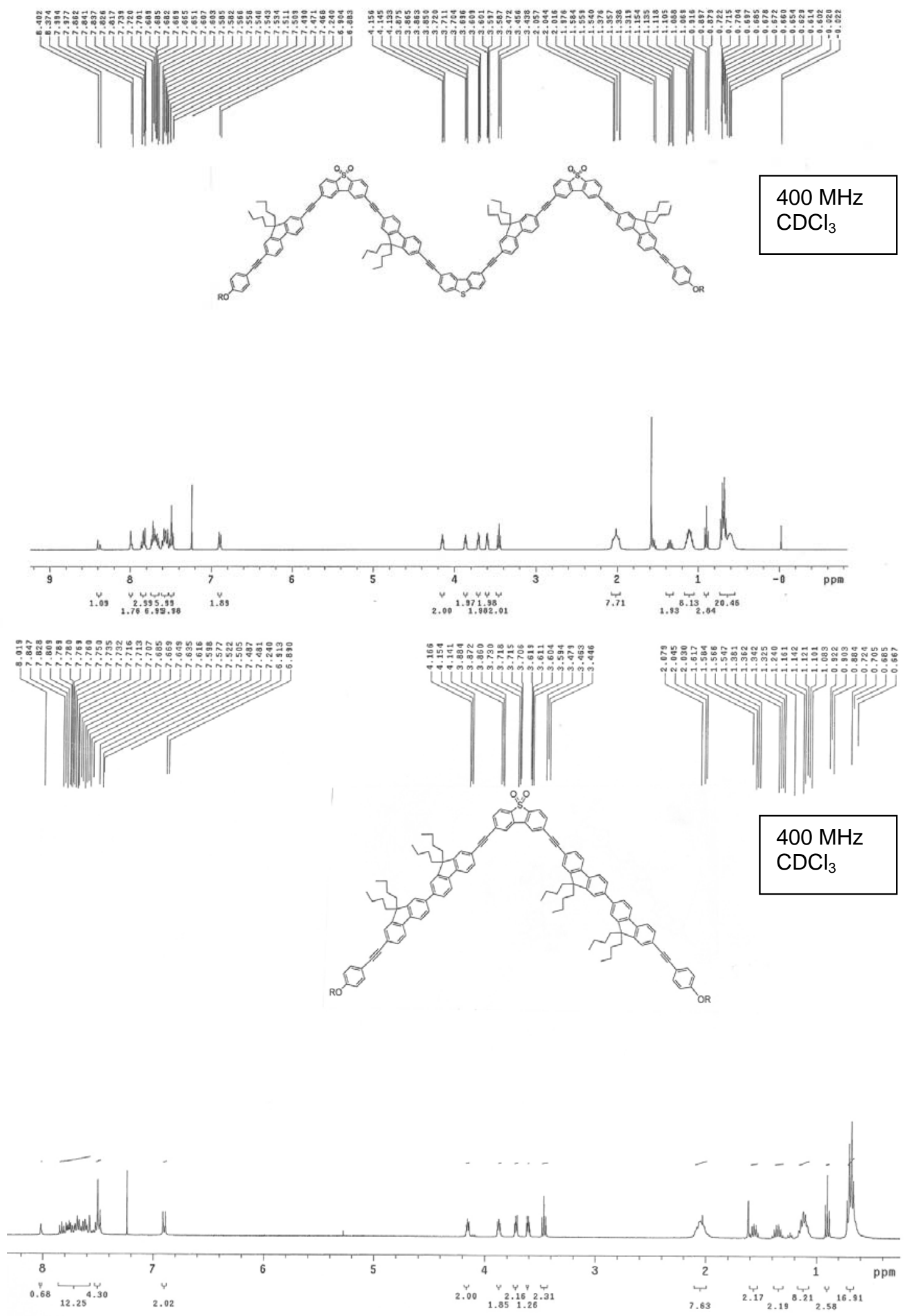
Supporting Information

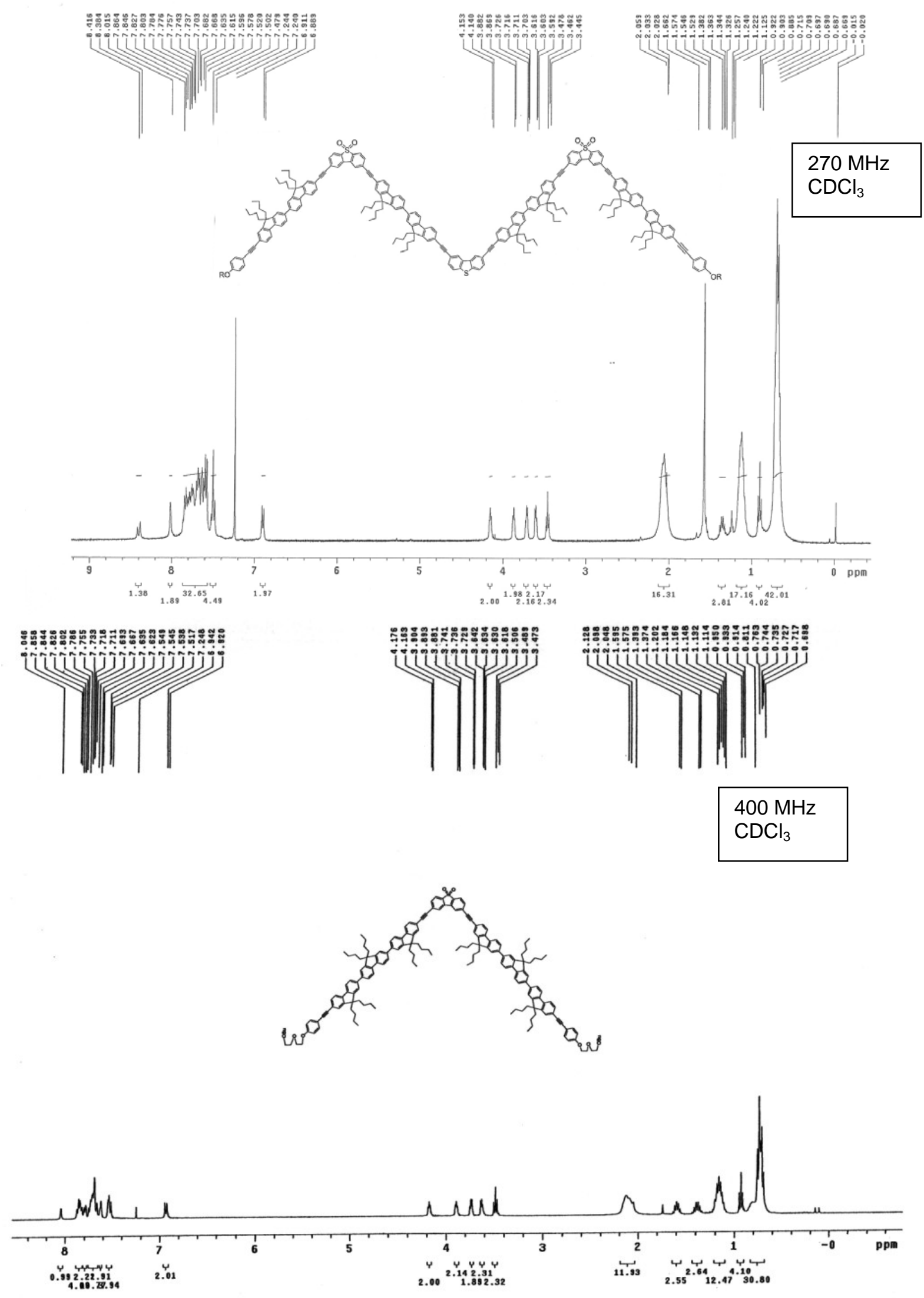




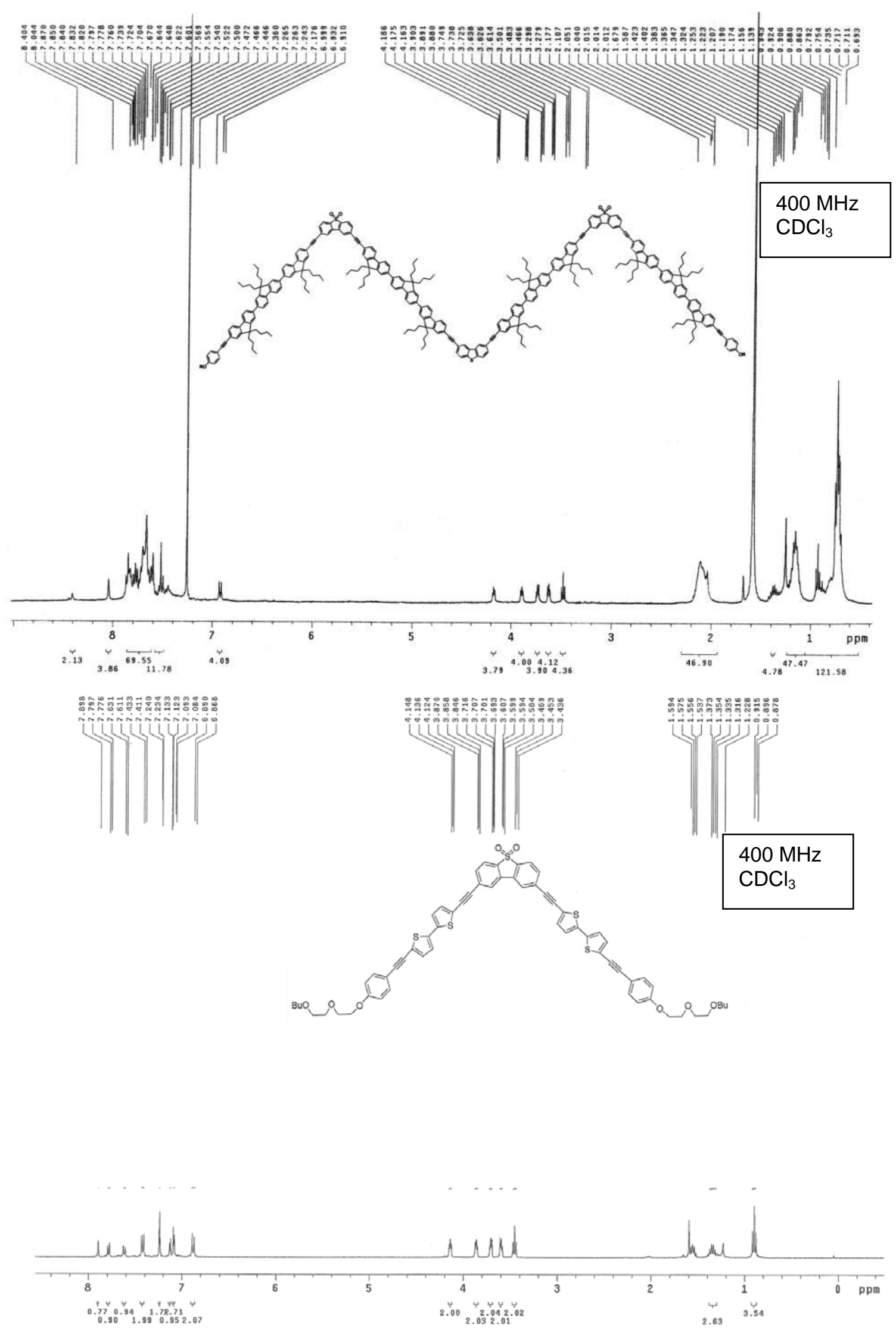




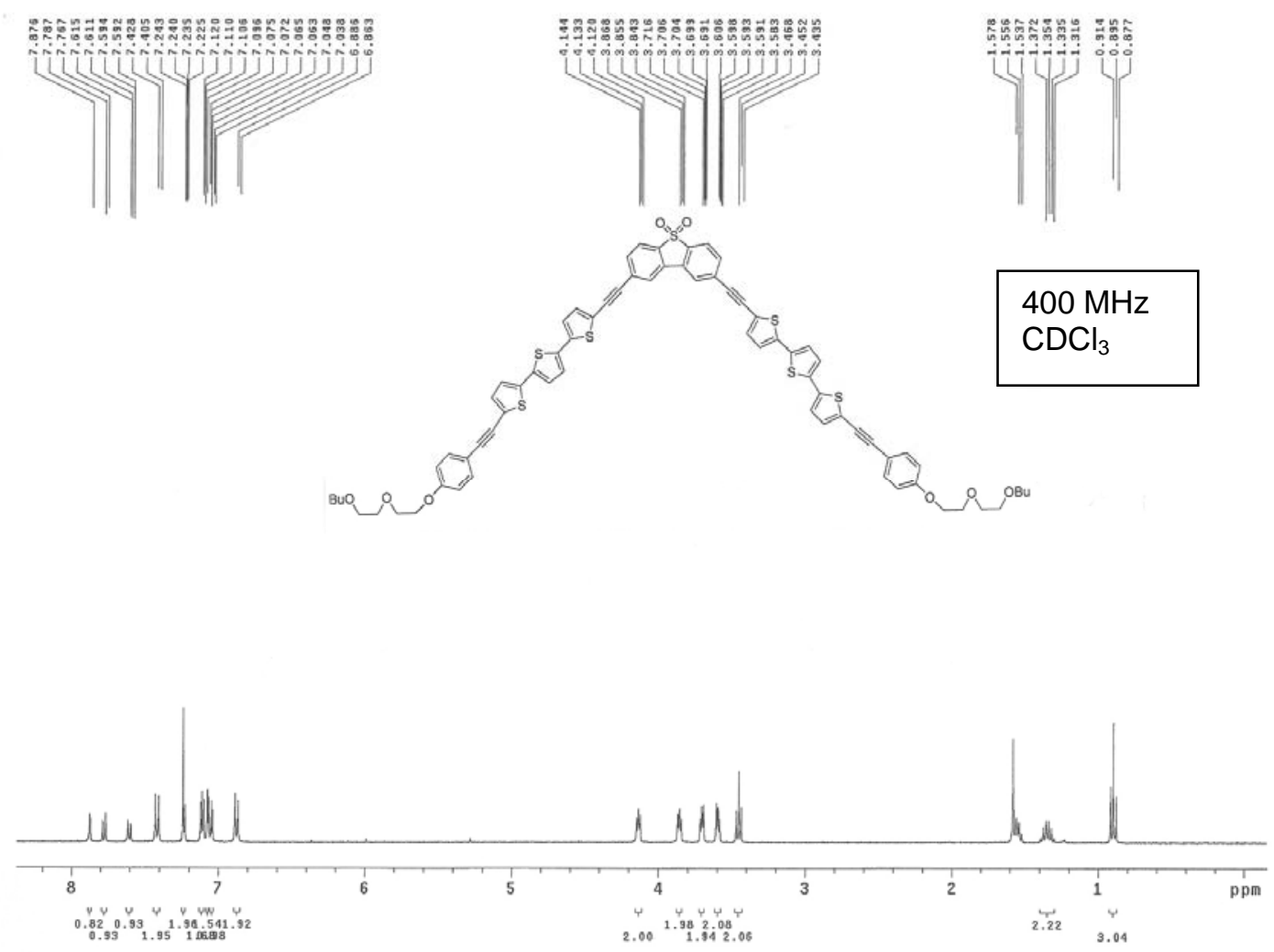

${ }^{13}$ C NMR Spectra of DA(n)s and D-Ar-A(n)s:
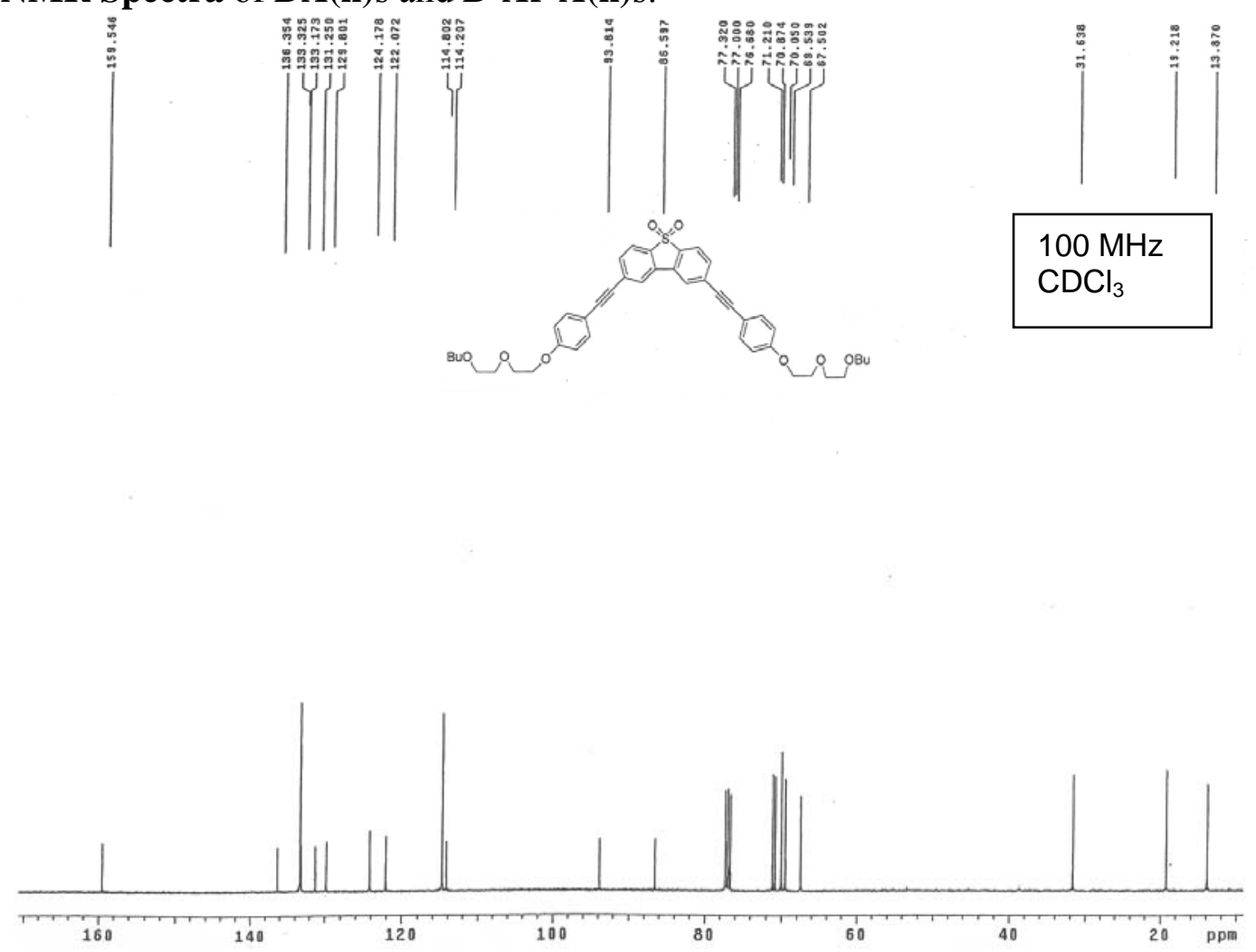
Supporting Information
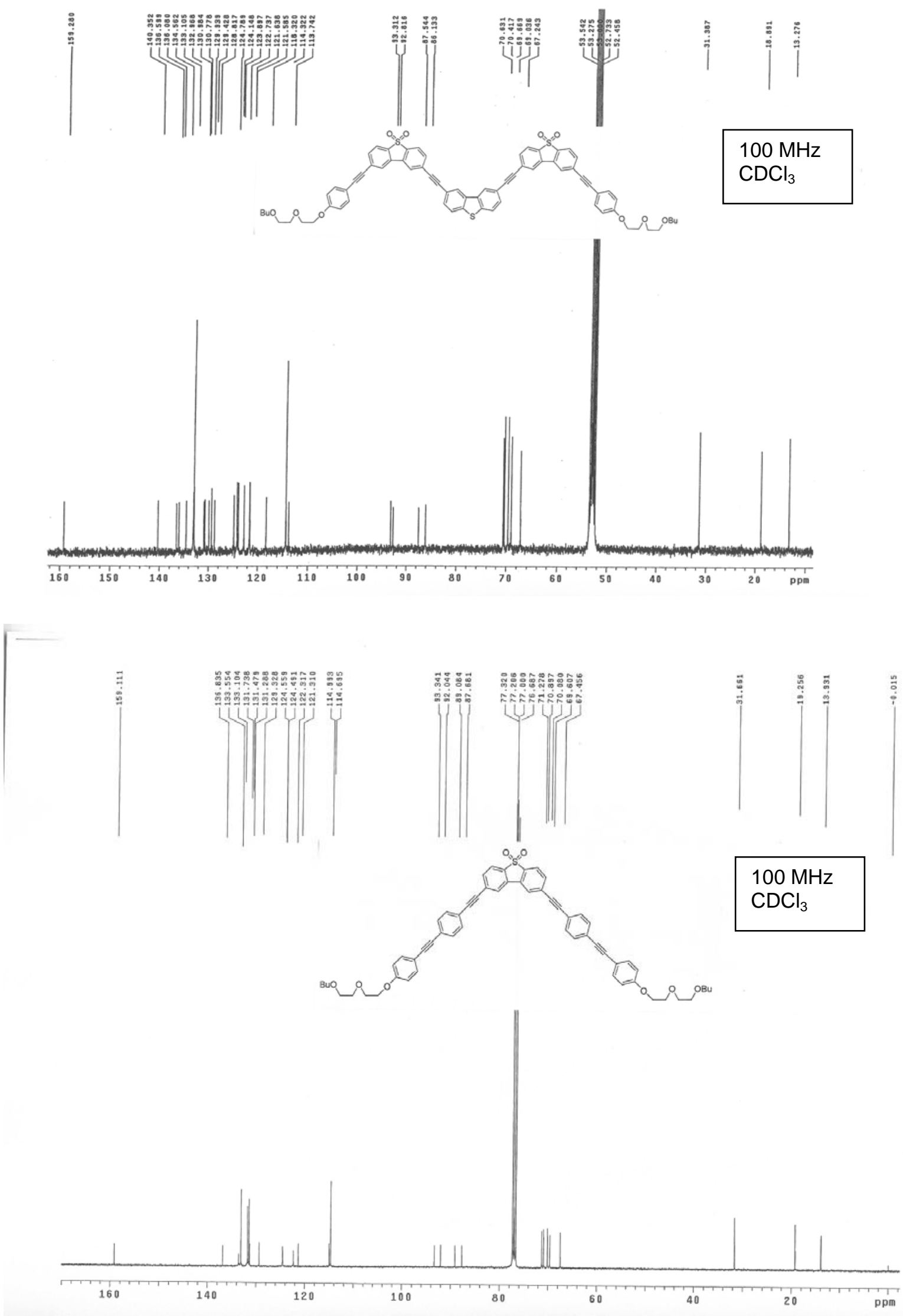

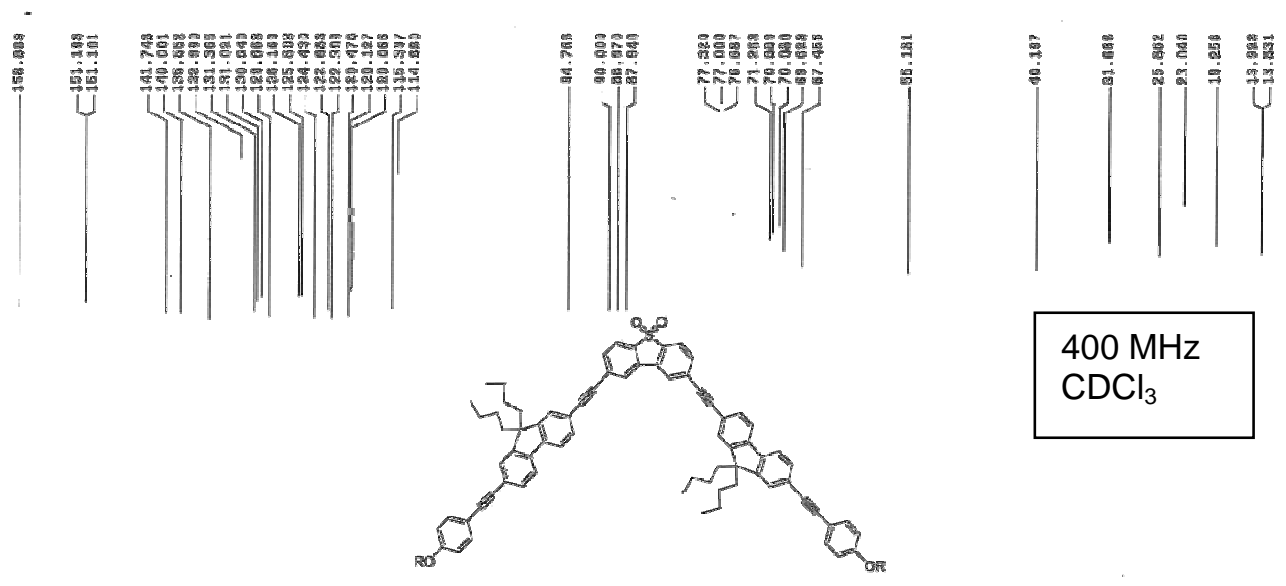

$400 \mathrm{MHz}$ $\mathrm{CDCl}_{3}$
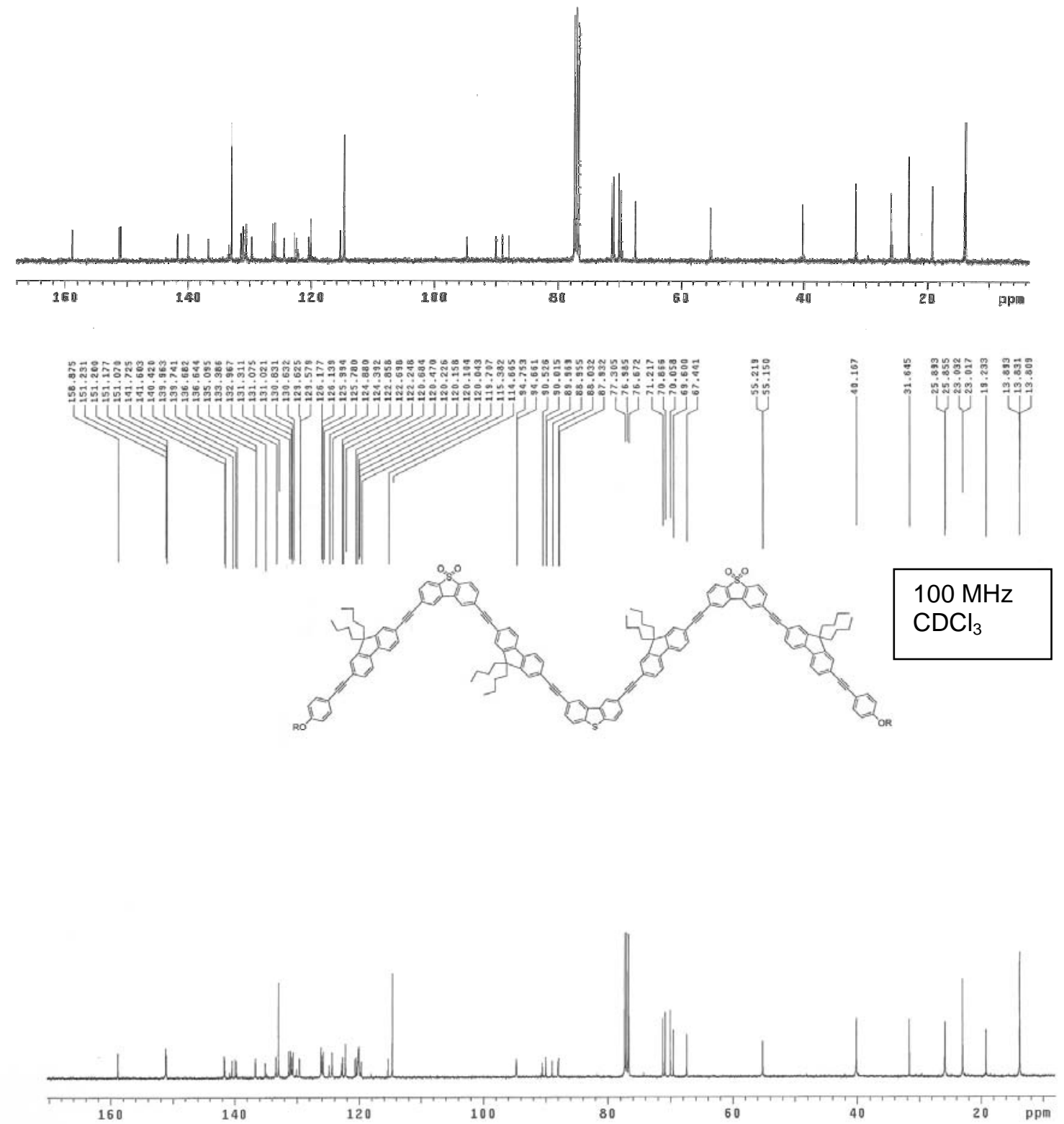


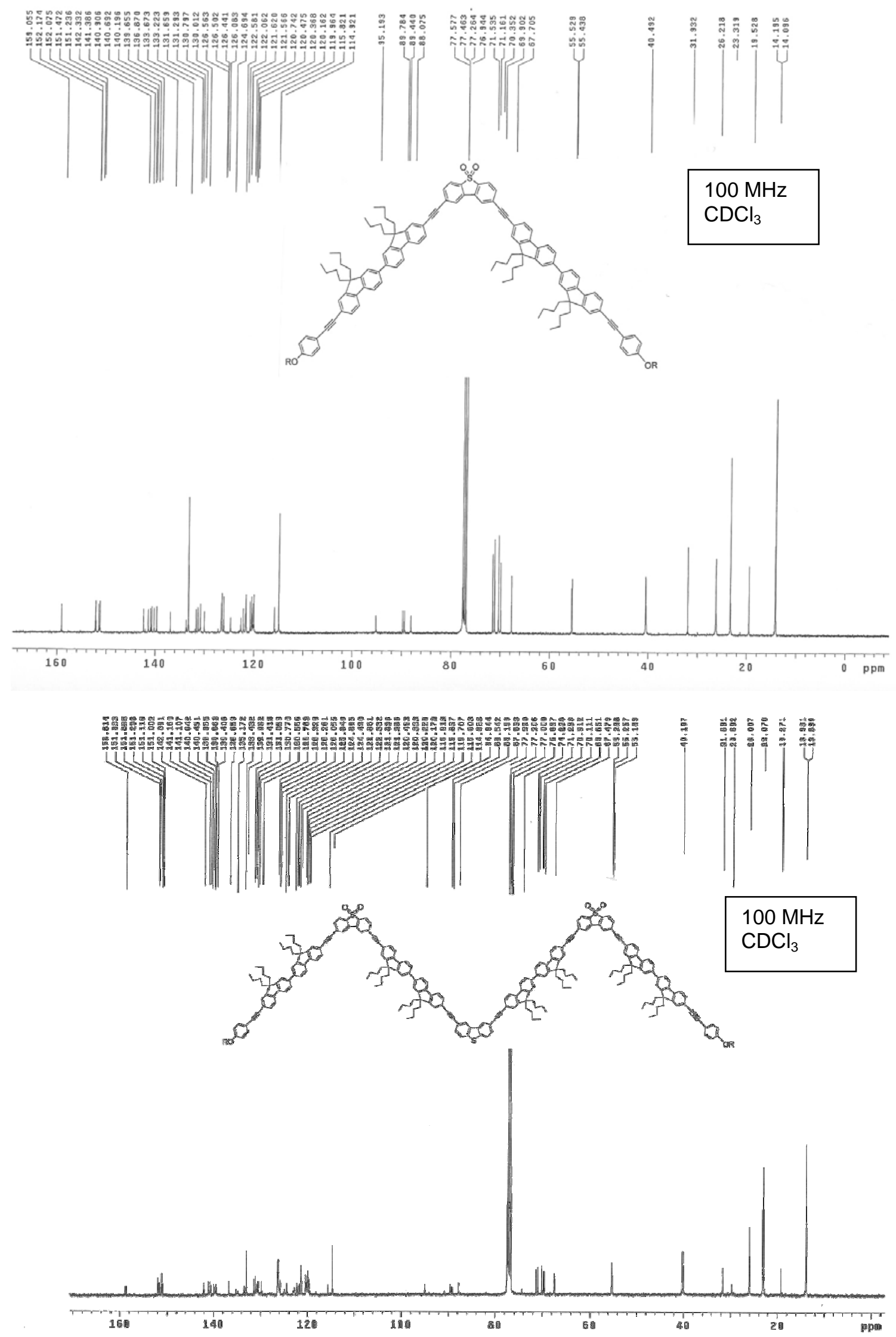


Supporting Information
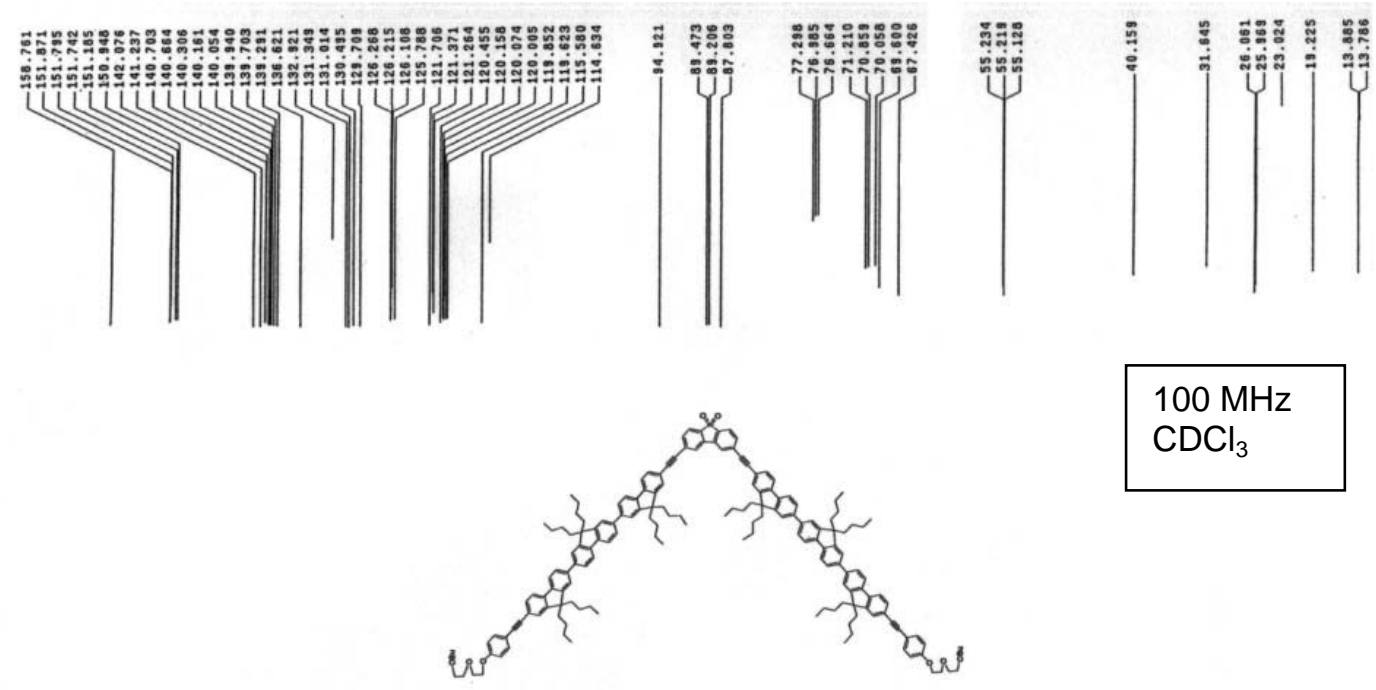

\section{$100 \mathrm{MHz}$ $\mathrm{CDCl}_{3}$}

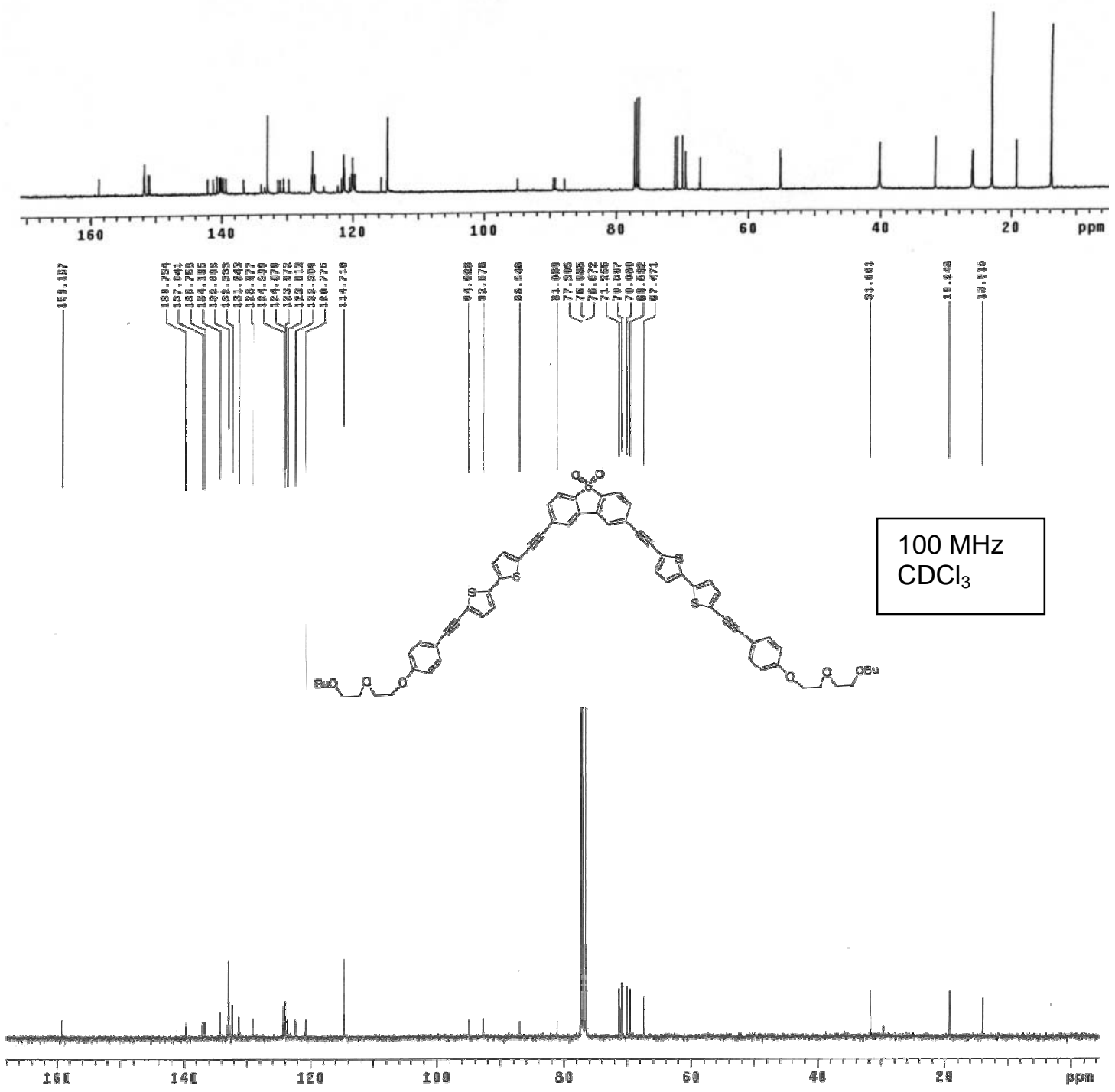


Supporting Information

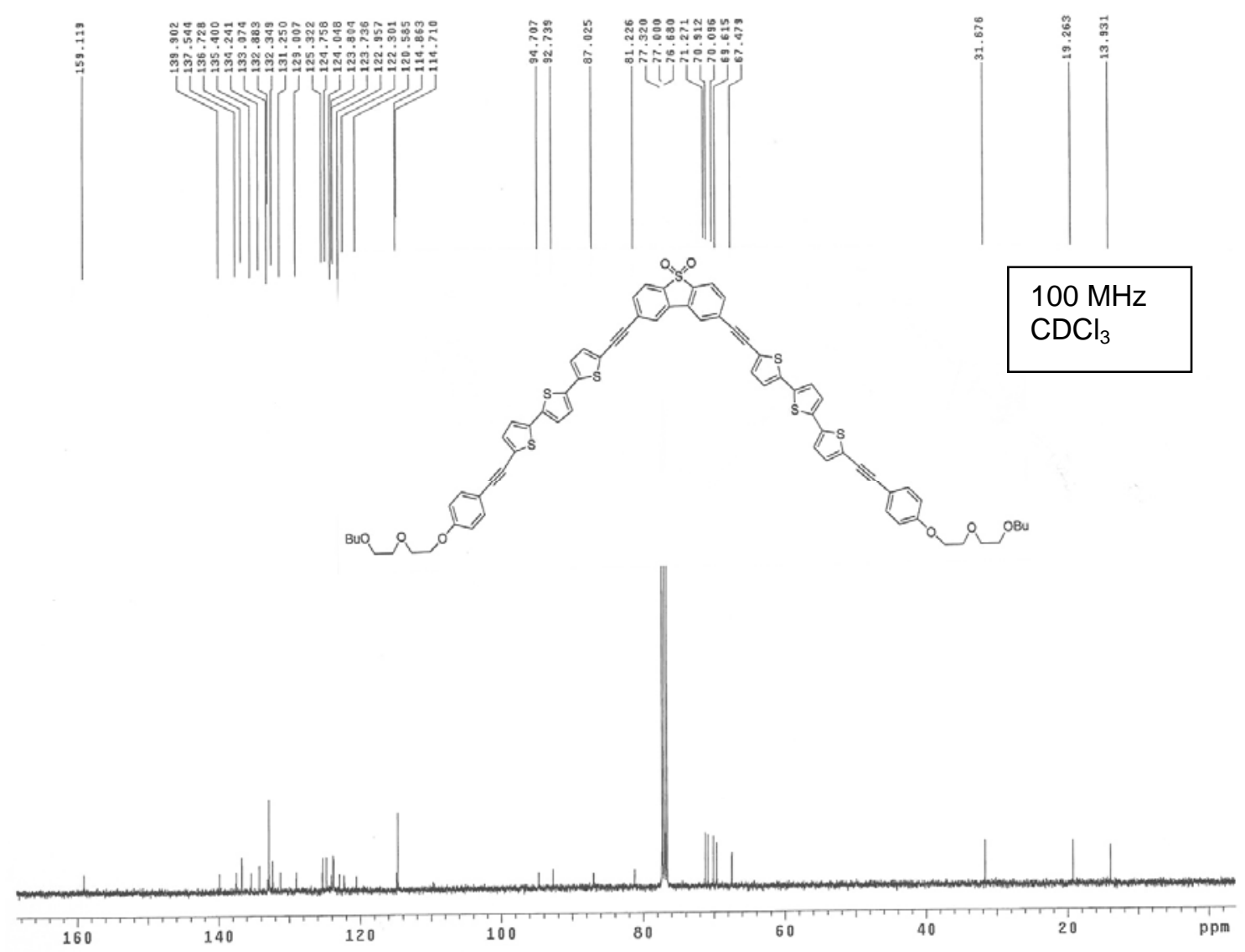

